Ana MIHALJEVIĆ

UDK 272 282.7:003.349.1

Staroslavenski institut

$811.163 .42 ’ 255$

Zagreb

ana.mihaljevic@stin.hr

27-36Becket, Thomas, sanctus

Izvorni znanstveni članak

Primljen: 31. ožujka 2019.

Prihvaćen: 9. listopada 2019.

\title{
SLUŽBA U ČAST SV. TOMI BECKETU U HRVATSKOGLAGOLJSKIM BREVIJARIMA
}

U radu se analizira jezik hrvatskoga crkvenoslavenskog prijevoda Službe u čast sv. Tomi Becketu. Tekst te službe sačuvan je u 21 hrvatskoglagoljskom brevijaru $\left(\mathrm{BrVb}_{1}, \mathrm{Bar}, \mathrm{Ber}_{2}, \operatorname{Mosk}, \mathrm{N}_{1}\right.$, Vat $_{10}$, Vat ${ }_{19}$, Vat, , Pm, Met, Mav, VO, Rom, Pt, Broz, Drag, Oxf, Pad, Vin, $\mathrm{N}_{2}$, Brit) u dijelu Proprium de tempore. Toma Becket engleski je svetac kojega slavi Katolička Crkva, a živio je u 12. stoljeću. Stoga hrvatskoglagoljski pisari nisu mogli upotrijebiti slavenski tekst Službe u čast sv. Tomi Becketu niti ga prevesti s istočnoga izvornika, nego su morali prevesti latinski izvornik. Riječ je o hrvatskoglagoljskome prijevodu tzv. Sarum službe, tj. teksta službe iz Sarumskoga brevijara (BrSar). U radu se objavljuju i latinski tekst izvornika i tekst hrvatskoglagoljske službe iz najstarijega hrvatskoglagoljskog I. vrbničkog brevijara $\left(\mathrm{BrVb}_{1}\right)$. Razlike osnovnoga teksta iz $\mathrm{BrVb}_{1}$ i tekstova iz ostalih brevijara navode se $\mathrm{u}$ kritičkome aparatu. Većina je razlika fonološka i morfološka, a leksičke su razlike rijetke. Hrvatskoglagoljski tekst prijevod je prvih dvaju i pol

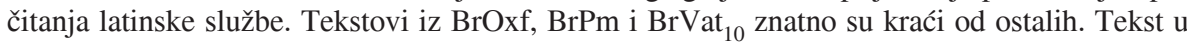
BrVat $_{19}$ nešto je kraći od ostalih, od kojih su tek neznatno kraći tekstovi u BrBar, BrMav i BrBroz. U pojedinim se tekstovima dodaju ili izbacuju pojedine riječi ili dijelovi teksta. Prijevod je vjeran izvorniku iako neki dijelovi rečenica nisu prevedeni. Pri prevođenju s latinskoga na hrvatski crkvenoslavenski osobit su problem oblici i strukture koje u tim jezicima nemaju isto značenje ili ulogu, oblici bez formalnoga korespondenta te pogotovo konstrukcije, zavisne rečenice i oblici koji u hrvatskome crkvenoslavenskom ne postoje. Ablativ apsolutni uglavnom se prevodi finitnom rečenicom s veznikom $i$ ili bez njega ili instrumentalom apsolutnim. Konstrukcija nominativa s infinitivom s glagolom video, 2. prevedena je u jednome primjeru kao rečenica s prilogom očito, a u drugome povratnim oblikom glagola vidêti i infinitivom. Gerundiv koji zamjenjuje gerund preveden je kao glagolska imenica. Veznik quia u ovome tekstu uvodi uzročne rečenice i preveden je veznikom êko. Latinski konjunktiv imperfekta u hrvatskoglagoljskim je tekstovima često preveden kondicionalom, ali u izričnim se rečenicama prevodi indikativom. Konjunktiv imperfekta perifrastične konjugacije aktivne preveden je infinitivom s imperfektom glagola imati. Konstrukcija akuzativa s infinitom uglavnom se vjerno prevodi, osobito u rečenicama koje izražavaju zapovijed. Konjunktiv prezenta preveden je indikativom. Red riječi prijevoda uglavnom prati red riječi latinskoga izvornika. Tekst je vjerojatno preveden krajem 13. st. jer je sv. Toma Becket živio krajem 12. st., a najstarija je sačuvana služba u njegovu čast iz $\mathrm{BrVb}_{1}$ s kraja 13. ili početka 14. st.

Ključne riječi: Služba u čast sv. Tome Becketa, hrvatski crkvenoslavenski jezik, hrvatskoglagoljski brevijari, latinski predložak, prijevodna tehnika, sv. Toma Becket 


\section{UVOD}

Toma (Thomas) Becket (London, 21. prosinca 1119. g. - Canterbury, Kent, 29. prosinca 1170. g.) svetac je iz 12. stoljeća koji se smatra jednom od najkontroverznijih osoba engleske povijesti zbog svojega kompliciranog odnosa s kraljem Henrikom II. Plantagenetom. Becket je bio engleski kancelar, a zatim je zbog velikoga prijateljstva između njega i Henrika te Henrikove vjere u njegove iznimne sposobnosti postao kenterberijski nadbiskup. Henrik je smatrao da cee uz Becketovu pomoć i podršku kao nadbiskupa postići da i u području crkvenih ovlasti kraljevi interesi budu ispred crkvenih. ${ }^{1}$ Međutim, nakon što je proglašen nadbiskupom, Becket u potpunosti mijenja svoj život i posve se podređuje Crkvi. Zbog sukoba s Henrikom nakon što izražava svoju vjernost papi, strahujući za vlastiti život, dobrovoljno odlazi u izgnanstvo u Francusku. Nakon šest godina dolazi do primirja između pape i Henrika te je Becketu obećan siguran povratak u Canterbury. Becket se vraća u Englesku, međutim, svjestan svojega teškog položaja - prema zapisima suvremenika - često najavljuje svoju smrt i mučeništvo. U kenterberijskoj katedrali 29. prosinca 1170. godine četvorica kraljevih vitezova ubijaju Becketa koji, navodno, odbija pobjeći i veseli se svojemu mučeništvu. Nakon smrti Becket postaje vrlo popularan i priče o njegovim čudesima šire se po cijeloj Europi te ga 1173. godine - dakle, samo tri godine nakon smrti - papa Aleksandar III. proglašava svetim. Godinu dana kasnije kralj Henrik II. pred Becketovim se grobom pokajao zbog svojih grijeha.

Kad je riječ o Becketu kao o svetcu, šest je elemenata njegove svetosti i njegova života koji se često ističu. ${ }^{2}$ Becket se opisuje kao homo novus, tj. ističe se njegovo preobraćenje kad je postao nadbiskup. Opisuje se kao bonus pastor, tj. dobri voditelj Crkve koji se žrtvuje za svoje ovčice. Smatra se i braniteljem Crkve - u pričama o njemu naglašava se njegova hrabrost u obrani njezina položaja. On je, naravno, slavljen i kao mučenik. Jedan od važnih uzroka njegove svetosti velik je broj navodnih čudesa nakon njegove smrti, kojih je u prvih deset godina prijavljeno čak $703,{ }^{3}$ a veliku je čudotvornost navodno imalo i pijenje napitka za koji se tvrdilo da je pripremljen od njegove krvi, tzv. Becketove vodice. ${ }^{4}$ Becketa je izrazito popularnim činilo to što su ljudi uočavali niz poveznica između njega i Krista, pri čemu se posebno isticalo njegovo mučeništvo, koje se doživljavalo kao novo rođenje u Kristu, a koje se dogodilo upravo u božićno vrijeme.

1 Usp. FARMER 1987: 420.

2 O razvoju njegova svetačkog kulta i o latinskim liturgijskim službama u čast sv. Tomi Becketu detaljnije v. BRAINERD SLOCUM 2004.

3 FARMER 1987: 420.

4 The Water of St. Thomas (BRAINERD SLOCUM 2004: 92). 


\section{SLUŽBE U ČAST SV. TOMI BECKETU}

Latinske liturgijske službe u čast sv. Tomi Becketu nastale su vrlo brzo nakon njegove kanonizacije. U kršćanskome kalendaru sv. Toma Becket slavi se na nekoliko datuma. Prvi je 29. prosinca ili večer uoči 29. prosinca, tj. dana njegova ubojstva za koji postoje tri različite službe. Drugi je datum 1. prosinca, dan na koji se slavi Becketov povratak u Englesku nakon šestogodišnjega izgnanstva u Francuskoj, a dvije su službe za 7. srpnja, dan kad su njegovi posmrtni ostatci preneseni u Canterbury. Liturgijsku službu uz prijenos Becketova tijela napisao je kenterberijski nadbiskup Stephen Langton. Službe su bile izrazito popularne i raširene u gotovo čitavoj Europi.

O popularnosti sv. Tome Becketa svjedoči i činjenica da je postojala posebna glazba za slavljenje njegova dana. Službu koju je ta glazba pratila napisao je Benedikt od Peterborougha, poznat i kao opat Benedikt, na temelju opisa Becketova života. ${ }^{5}$ Smatra se da je riječ o iznimno kvalitetnoj i umjetnički vrijednoj službi jer nije nastala iskorištavanjem postojećih napjeva, nego je originalno Benediktovo djelo.

Usporedbom teksta hrvatskoglagoljske službe s tekstovima latinskih služba u čast sv. Tomi Becketu može se utvrditi da je hrvatskoglagoljska služba $n(a) s(v e) t$ (a)go tomasa $\cdot$ službi iĉi ot $m(u) \check{c}($ eni) $k b$ b(i)sk(upb) nastala na temelju tzv. službe Sarum, ${ }^{6}$ tj. službe iz Sarumskoga brevijara (BrSar). Riječ je o službi koja je općenito bila najpopularnija i najraširenija u Europi, a koja se slavi 29. prosinca, na dan Becketova ubojstva. Služba Sarum nešto je kraća od Benediktove, ali se proširila u većini zemalja. Nastala je u katedrali u Salisburyju, a upotrebljavala se i u kraljevskoj kapeli te je zbog toga postala tako popularnom. Postoje i zapisi o naredbama u kojima se traži da se ta služba dodatno prepisuje u Oxfordu i Londonu. Osobito se proširila u Francuskoj za vrijeme vladavine Plantageneta, ${ }^{7}$ a zatim i u cijeloj Europi, ponajprije zahvaljujući djelovanju cistercita.

Izvorna se latinska služba sastoji od devet čitanja u kojima je opisan Becketov život. ${ }^{8}$ Prvo čitanje slavi njegove višestruke sposobnosti - i kao kancelara, i kao nadbiskupa, i kao velikoga vjernika. Navodi se da je nakon zaređenja

5 REAMES 2000: 561.

6 Usp. »Sarumski obred je bio način slavljenja rimskog obreda u Engleskoj do reformacije. $\mathrm{U}$ bitnome se radi o istom tradicionalnom rimskom obredu (kodificiranom kao tridentska Misa), ali s mjesnim varijacijama prema regionalnim običajima i tradicijama.« URL: http:// christusrexhrvatska.blogspot.com/2013/10/razlike-izmeu-tradicionalne-latinske.html (17. 11. 2019.).

7 O položaju sv. Tome Becketa za vrijeme Plantageneta v. WEBSTER; GELIN 2016.

8 Opis procesije koja je prethodila službi v. u BRAINERD SLOCUM 2004: 209. 
postao novim čovjekom, potajno je nosio kostrijet do koljena i pokušao je poboljšati položaj Crkve. Opisuje se Becketov sukob s kraljem zbog neslaganja u poimanju odnosa crkvene i svjetovne vlasti. Becket je odbio poslušati kralja i zbog toga trpio teške posljedice. Kad mu je kralj zaprijetio smrću, napustio je Englesku i pod zaštitom pape Aleksandra otišao u samostan u Pontignyju u Francuskoj. Drugo čitanje govori o tome kako su Becketu zaplijenjena sva imanja i kako su nevolje proživljavali i njegovi rođaci i prijatelji bez obzira na dob, spol, položaj i bogatstvo te su i oni protjerani. Ističe se da je on sve otrpio za Kristovo ime i da je sve oko sebe poučavao da je svakomu hrabrom čovjeku cijeli svijet domovina. U trećemu čitanju navodi se da mu je kralj poslao prijeteće pismo i da je Becket zbog toga otišao iz Pontignyja. Prije odlaska iz Pontignyja s nebesa mu je javljeno da će se vratiti u svoju crkvu u punome sjaju slave i da će postati mučenik. Po odlasku iz Pontignyja primio ga je francuski kralj s velikim počastima. Šest je godina proveo u izgnanstvu. U četvrtome čitanju riječ je o ponovnome uspostavljanju mira. Opisuje se Becketov povratak u Englesku i navodi se da ga je kralj ponovno mučio. U petome čitanju opisan je dolazak četvorice zlih muškaraca u Canterbury. Ističe se da ih je Becket dočekao ostavljajući otvorena vrata katedrale. Navode se njegove riječi kojima dobrovoljno prihvaća mučeništvo. U šestome čitanju navode se njegove posljednje riječi kojima se predaje mučeništvu, opisuje se njegova smrt i najavljuju njegova čudesa. Kao sedmo čita se Evanđelje po Ivanu 10: 11-16 i 14. homilija pape Grgura Velikoga. U nastavku se teksta opisuju čudesa po njegovoj smrti i njegova važnost.

\section{HRVATSKOGLAGOLJSKA SLUŽBA U ČAST SV. TOMI BECKETU}

Hrvatskoglagoljska liturgijska Služba u čast sv. Tomi Becketu - služba n(a) $s(v e) t(a)$ go tomasa $\cdot$ službi iĉi ot $m(u) \check{c}($ eni) $k b b(i) s k(u p b)$ sačuvana je u većini hrvatskoglagoljskih brevijara koji sadrže temporal (Proprium de tempore). To su: Brevijar Vida Omišljanina (BrVO) 57c-58d, Vatikanski brevijar Illirico 5 $\left(\mathrm{BrVat}_{5}\right)$ 33a-33d, II. novljanski brevijar $\left(\mathrm{BrN}_{2}\right) 33 \mathrm{~d}-34 \mathrm{c}$, Baromićev tiskani brevijar (BrBar) 111a-112a, Pašmanski brevijar (BrPm) 34a-34d, I. vrbnički brevijar $\left(\mathrm{BrVb}_{1}\right)$ 42b-43b, Rimski brevijar D 215 (BrRom) 86r-88v, II. beramski brevijar $\left(\right.$ BrBer $\left._{2}\right)$ 45b-46b, Dragućki brevijar (BrDrag) 27a-27d, Oksfordski brevijar - misal (BrOxf) 32a-32c, Brevijar popa Mavra (BrMav) 32d-34a, Vatikanski brevijar Vat. Slav. 19 (BrVat $\left.{ }_{19}\right)$ 30b-31a, Moskovski brevijar (BrMosk) 33a-33d, Brevijar Metropolitanske knjižnice u Zagrebu MR ${ }_{161}$ (BrMet) 47b-48b, I. novljanski brevijar $\left(\mathrm{BrN}_{1}\right) 31 \mathrm{a}-31 \mathrm{~d}$, Padovanski brevijar (BrPad) 37a-38c, Prvotisak brevijara (BrPt) 33b-34a, Brozićev brevijar (BrBroz) 103a-104a, Vinodolski (Kukuljevićev) brevijar (BrVin) 35c-36b, Vatikanski brevijar Illirico 
10 (BrVat ${ }_{10}$ )30a-31a, Britanski brevijar (BrBrit) 39a-39d. Riječ je o službi koja je na hrvatski crkvenoslavenski jezik prevedena s latinskoga. ${ }^{9} \mathrm{U}$ svim je tekstovima riječ o istome prijevodu i svi su oni vrlo slični, uz stanovite razlike, većinom fonološke i morfološke te rjeđe leksičke. ${ }^{10}$ Kao polazni je tekst u ovome radu uzet tekst iz BrVb ${ }_{1}$, koji je najstariji, te su s njime uspoređeni tekstovi iz drugih brevijara, dok se u bilješkama navode njihove jezično i tekstološki zanimljive razlike. Od ostalih tekstova dužinom znatnije odstupa tekst u BrOxf, koji je znatno kraći od ostalih i završava pred kraj latinskoga prvog čitanja. Kraće čitanje, prijevod teksta otprilike jednoga i pol latinskoga čitanja, sadržavaju još BrPm i BrVat ${ }_{10}$, dok BrVat ${ }_{19}$ završava Becketovom tvrdnjom u drugome čitanju, da je svakomu hrabrom čovjeku cijeli svijet domovina. Završni dio nemaju BrBar BrMav i BrBroz koji su neznatno kraći od ostalih brevijara.

Za opis grafije i fonologije teksta primjenjiva je tvrdnja: Grafijske i fonološke pojave i razlike u njima među kodeksima ne mogu biti pokazatelj jezične konzervativnosti ili pomlađenosti prijevoda. One više ovise o tome kakav je stav prepisivača kodeksa (ili njegova dijela) prema pravopisnoj i jezičnoj normi nego o samome tekstu o kojemu je riječ. U tom pogledu nema razlike između ovoga teksta i ostalih dijelova u misalima. Ako se u drugim dijelovima kodeksa apostrof unosi između proizvoljnih suglasnika, tako će biti i u ovom tekstu; ako se u drugim dijelovima jaki poluglas (ne) vokalizira kao $a$, tako će biti i ovdje; ako se u drugim dijelovima kodeksa jat odražava kao $e$ ili $i$, tako će biti i ovdje itd. Ti podatci mogu biti važni za dataciju i lokalizaciju pojedinoga kodeksa, ali ne pokazuju koliko je dobro prevoditelj teksta s latinskoga poznavao hrvatsku crkvenoslavensku normu « (KOVAČEVIĆ; MIHALJEVIĆ; SUDEC 2010: 366). U fonologiji zanimljiva je ipak pojava zamjene

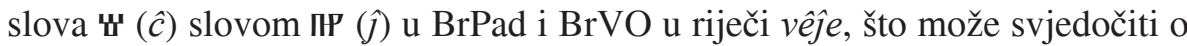
tome kako se slovo $\mathrm{w}$ izgovaralo. ${ }^{11}$

U morfologiji zanimljivi su noviji genitivni nastavci u pridjevskoj deklinaciji koji se pojavljuju u nekim brevijarima. U deklinaciji broja jedan pojav-

\footnotetext{
${ }^{9}$ Takvim se tekstovima prvo bavio Josip Tandarić, koji je zaključio da su glagoljaši dobro poznavali latinski i imali ustaljene norme pri prevođenju s latinskoga na hrvatski crkvenoslavenski jezik (TANDARIĆ 1993: 70).

10 Takva je situacija odraz općenitoga pristupa tekstovima u mlađim hrvatskoglagoljskim brevijarima. Govoreći o tekstovima sv. Tome Akvinskoga autori iznose tvrdnju koja vrijedi i za ovaj tekst: »Postojeće razlike rezultat su želje da se tekst ispravi i približi latinskomu izvorniku, da se stariji oblici zamijene mlađima koji će čitatelju biti razumljiviji ili su jednostavno pogreške nastale prepisivanjem sa starijega glagoljskoga predloška.«(KOVAČEVIĆ; MIHALJEVIĆ; SUDEC 2010: 364).

${ }^{11}$ V. MIHALJEVIĆ 2018: 17-18; GADŽIJEVA; KOVAČEVIĆ; MIHALJEVIĆ; POŽAR; REINHART; ŠIMIĆ; VINCE 2014: 64-65.
} 
ljuju se u BrVin i $\mathrm{BrN}_{1}$ : ot ednoga. U BrMosk noviji nastavak pojavljuje se u deklinaciji broja drugi: dr(u)goga. I u deklinaciji broja treći pojavljuju se noviji nastavci - u BrVat ${ }_{5}$, BrMosk i BrRom: tretoga. U BrMet, BrPt, BrBer ${ }_{2} \mathrm{i}$ BrBrit nastavak -oga pojavljuje se u deklinaciji pridjeva crêkveni: cr(ê)kvênoga $\mathrm{BrBer}_{2}$ crikvenoga $\mathrm{BrPt}$ cr(ê)kv(e)noga BrMet crêkvenoga BrBrit. $\mathrm{U} \mathrm{BrN}_{2}$ susrećemo oblik s nastavkom -aga, koji je vjerojatno pogreška zbog supostojanja oblika koji završavaju na -oga i -ago: $\operatorname{cr}(\hat{e}) k v e ̂ n a g a$. U BrMosk pojavljuje se oblik sa zamjeničkim nastavkom -ogo: cr(ê)kvenogo. Pridjev cistercitski također se pojavljuje s nastavkom -oga $\mathrm{u} \mathrm{BrVat}_{5} \mathrm{i}_{\mathrm{BrPt}}$ česteriênskoga $\mathrm{BrVat}_{5}$ čistêriênskoga BrPt. U BrPt potvrđen je i oblik: ponciênskoga, dok u BrVat - pod utjecajem zamjeničke deklinacije - taj primjer glasi: ponciênskogo. U tekstovima su potvrđene četiri inačice trećega lica jednine aorista glagola biti: bê, bistb, bi, bisi. Prvo lice prezenta u većini brevijara ima nastavak -mo: dovlêemo, ali u $\mathrm{BrN}_{2}$ čuva se stariji nastavak - $m$ : dovlêem'. Uz dvojinski oblik imenice nogu pojavljuje se dvojinski oblik: plesnu. Imenica têlo sklanja se prema glavnoj promjeni: têlê/telê, za razliku od imenice nebo koja se sklanja kao imenica $s$-osnove: $s n(e) b(e) s e$. U tekstovima se čuva nastavak nominativa jednine muškoga roda participa prezenta -e: r(a)bot(a)e, nastoe, ugaždae, boe. U pridjevskoj deklinaciji vidljivi su utjecaji zamjeničke deklinacije u primjeru riječi cr(ê)kvenoi, dok se u BrMosk čuva izvorni oblik crekvenêi. U sintagmi vsakomu krêpkomu zamjenički je nastavak -omu zamijenio izvorni pridjevski nastavak -umu, što je u hrvatskome crkvenoslavenskom općenita pojava. ${ }^{12}$ Dativ jednine imenice gospod u svim brevijarima glasi g(ospode)vê, osim u BrVat $_{5}$ u kojemu glasi $g($ ospod) $u$.

Razmjerno su rijetka leksička odstupanja. U nekoliko se brevijara (BrVO $\mathrm{N}_{1}$ Vat $_{19} \mathrm{Vat}_{5} \mathrm{~N}_{2}$ Vat $_{10}$ ) umjesto obleža iz osnovnoga $\mathrm{BrVb}_{1}$ pojavljuje oblik uspê, u drugome dijelu brevijara (BrMav Pad Pm Vin Met) ne uboê se, a samo u BrOxf riječ ubêža. Riječ je o uvodnome dijelu teksta kojemu nije utvrđen latinski predložak. Kao prijevod latinskoga superlativa carissimi u $\mathrm{BrN}_{2}$ pojavljuje se vzlûblena, dok je u ostalim brevijarima potvrđen komparativ $m$ (i)lêiša . $\mathrm{U} \mathrm{BrVat}_{5}$ odstupa se od latinskoga recolere i pojavljuje se izraz $i$ čudêsêhb umjesto čisti - kako je u većini brevijara. U tome primjeru od ostalih odstupa i BrVat ${ }_{10}$ - oblikom čis'toti. BrPad sadržava prêvzide na mjestu na kojemu ostali brevijari imaju prêd'teče, oblik koji je bliži latinskomu percurrat. Prema latinskome devotus u mnogim se brevijarima $\left(\mathrm{BrN}_{2} \mathrm{Vat}_{19}\right.$ Drag Mosk Pm Oxf) pojavljuju različite inačice pridjeva zbožanb: s'bož(a)n u $\mathrm{BrN}_{1}$; kao riječ s drukčijim predmetkom vzbožans u BrBar i BrBroz, dok se u BrVat ${ }_{10}$

${ }^{12}$ GADŽIJEVA; KOVAČEVIĆ; MIHALJEVIĆ; POŽAR; REINHART; ŠIMIĆ; VINCE 2014: 169. 
piše razdvojeno od predmetka: $s a \cdot b(o) \check{z}(a) \mathrm{n}_{b}$. $\mathrm{U} \mathrm{BrVb}_{1}$ susrećemo pogrešnu riječ vzmožbn'. U BrVat ${ }_{5}$ pisar vjerojatno tu riječ pogrešno prepoznaje kao blažen i piše $b l(a) z ̌(e) n b$. Riječ caulis u jednome je dijelu brevijara prevedena kao ograda, a u drugome dijelu kao: osêce $\mathrm{BrN}_{2} \mathrm{Vat}_{5} \mathrm{~N}_{1}$ osice BrMosk osici BrPm osicê BrBar Broz Oxf Vat ${ }_{10}$ osêci BrDrag. Za latinski potestas u Br$\mathrm{Vat}_{5}$ stoji vlastb, dok je u ostalim brevijarima oblastb. $\mathrm{U} \mathrm{BrN}_{2}$ i BrVat $_{19}$, kao prijevod oblika latinske riječi rex pojavljuju se oblici imenice kralb: k'ralemb $\mathrm{BrN}_{2}$, kralemb $\mathrm{BrVat}_{19}$ k'ralb $\mathrm{BrN}_{2}$ kralb $\mathrm{BrVat}_{19}$ k'ralb $\mathrm{BrN}_{2}$ kralû $\mathrm{BrN}_{2}$, dok je u ostalim brevijarima riječ o oblicima imenice cêsarb. Prijevod latinskoga archiepiscopus u dijelu je tekstova arhibiskup, a u dijelu arhiepiskup: ar'hiepisk(u)pi $\mathrm{BrBer}_{2}$ ar'hibis 'ku〈pi $\rangle \mathrm{BrN}_{2}$ arhib(i)skupi $\mathrm{BrVat}_{5}$ ar'hibiskupie BrMosk arhib(i)skupii BrBar arh(i)b(i)sk(u)pi BrPm ar'hieb(i)sk(u)pii BrMav ar'hibiskupii BrRom arhib(i)sk(u)pi $\mathrm{BrN}_{1}$ arhib(i)sk(u)pii $\mathrm{BrBroz}$ arhib(i)skupii $\mathrm{BrPt}$ ar'hib(i)sk(u)pii $\mathrm{BrVat}_{19}$ arhibisk(u)pii BrVin arhibiskupie BrDrag arhieb(i)sk(u)pii (!) BrMet; arhiepiskupu $\mathrm{BrVb}_{1}$ ar'hib(i)sku(pu) $\mathrm{BrN}_{2}$ arhibiskupu BrVat ${ }_{5}$ Vin Drag ar'hibiskupu BrMosk arhib(i)sk(u)pu BrBar Broz $\mathrm{N}_{1}$ arhibisk(u)pu BrMav arhib(i)skupu BrPt b(i)sk(u)pu BrVat ${ }_{19}$ arhieb(i)sk(u)pu BrMet arhiepiskupi BrBrit. U BrBroz zabilježen je hrvatski glagol gov(o)r(i)̌̌e umjesto crkvenoslavenskoga glagola g(lago)laše prema latinskome asserens. Umjesto riječi truždan' prema latinskome affectus - u BrBroz i BrBar pojavljuje se oblik utruent. U BrPt i BrDrag umjesto rastegnen' prema latinskome attritus stoji pridjev rastrgnenb. U dijelu brevijara $\left(\mathrm{BrN}_{2} \mathrm{Vat}_{5} \mathrm{Pm} \mathrm{N} \mathrm{Drag}_{1} \mathrm{Vat}_{10}\right.$ Mosk) umjesto rashicahu prema latinskome vastantur pojavljuje se oblik razdrušahu, dok se u BrBroz i BrBar pojavljuje oblik razdrušev(a)hu. U BrPm pojavljuje se riječ sela umjesto njivi prema latinskome praedia. Umjesto riječi velikimi - kako bi se naglasila iznimna veličina izražena latinskim pridjevom immensis - u BrVat ${ }_{19}$ pojavljuje se riječ prevalikimi. Umjesto izvoli prema latinskome censuit $\mathrm{u}$ nekim se brevijarima $\left(\mathrm{BrVat}_{5}\right.$ Pm Bar Broz Vat $\left.{ }_{10}\right)$ pojavljuje oblik voli, a u drugima $\left(\mathrm{BrN}_{1}\right.$ Vin Drag) volê. Latinska riječ tacitis u različitim se brevijarima prevodi kao kosneniem ' $\mathrm{BrVb}_{1}$, kasneniem' BrVO kos 'nutiemb $\mathrm{BrN}_{2} \mathrm{Vat}_{5}$ Mosk, kosnutiemb BrBar Broz $\mathrm{N}_{1}$ Vin Drag. U BrMav kao prijevod latinskoga inflecteret pojavljuje se oblik uklopil umjesto priklonil, kako stoji u ostalim brevijarima. Latinske imenice iniuria i contumelias u dijelu se brevijara prevode imenicom sramota, a u dijelu drugim imenicama. Latinski contumelias u BrMosk prevodi se kao s'ramoĉeniemb, a u BrDrag kao sramoĉe. Imenica iniuria prevodi se u BrN ${ }_{2}$ Vat $_{5} \mathrm{~N}_{1}$ Bar Broz kao vaĉinoû, a u BrMosk i BrDrag riječju taĉinoû, moguće kao rezultat pogrešnoga prijepisa riječi vaĉinoû. Rezultat je vjerojatno pogrešnoga prijepisa i riječ četirêh' u BrVO prema latinskome quosdam, što je u ostalim brevijarima prevedeno kao eterêh'. Kao prijevod latinskoga 
perturbare u BrMav pojavljuje se riječ spuditi umjesto glagola smutiti, koji se pojavljuje u drugim brevijarima. $\mathrm{U}$ BrVat ${ }_{5}$ pojavljuje se pridjevni oblik z(e)m(a)lna umjesto imenice zemla prema latinskome solum. U BrPm prema latinskome divina umjesto vjernijega prijevoda $b(o) z ̌ i m b$ pojavljuje se pridjev $b(l a) \check{z}(e) n i$. Umjesto participa glagola vshicâûce u BrVat $_{5}$ i BrPt pojavljuje se particip glagola s drukčijim predmetkom: rashiçâ̂ce prema latinskome diripiuntur. Crkvenoslavenska zamjenica iže zamijenjena je hrvatskom ki u BrBroz i BrMav kao prijevod latinskoga quicumque. $\mathrm{U} \mathrm{BrVat}_{10}$ umjesto riječi pogneten' pojavljuje se riječ poginetb prema latinskome participu lacessitus. Druge se riječi pojavljuju vjerojatno zbog pogrešno pročitanoga teksta i u slje-

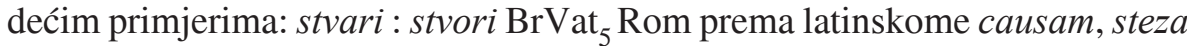
: sveza BrVat $_{19}$ prema latinskome exegit, zaslan' : zas 'tanb BrMosk zbstanb (!) BrBer $_{2}$ prema latinskome actus, strasti : starosti BrVat $_{5}$ prema latinskome supplicii, prêšbdše : prived(o)še BrBrit prema latinskome transito.

$\mathrm{U}$ pojedinim su tekstovima izostavljene pojedine riječi: u BrDrag - računa; u BrVO - bis(tb) i s n(e)b(e)se; u BrPm - gospod'skimi; u BrMav g(ospod)ni; u $\mathrm{BrBer}_{2}$ i BrBrit - rabotaniê i učiti; u BrBrit - iĉi; u $\mathrm{BrN}_{1}-n e$ oĉe, koliždo i ga; u BrVin - ne oĉe; $\mathrm{u} \mathrm{BrVat}_{5}$ - koliždo; $\mathrm{u} \mathrm{BrVat}_{19}$ - vrêmene i lêti; u BrPt - listi.

Rjeđe se izostavljaju i sintagme ili dijelovi rečenice: $\mathrm{u} \mathrm{BrN}_{2}, \mathrm{BrVat}_{5}$, BrMosk, BrPm, BrBar, BrBroz i BrVat ${ }_{19}-n(a)$ s(ve)t(a)go tomasa službi iĉi ot $m(u) \check{c}\left(\right.$ eni) kb b(i)sk(upb); $\mathrm{u} \mathrm{BrN}_{2}$ - se do dimai - oce $; \mathrm{u} \mathrm{BrVat}_{5} \mathrm{i} \mathrm{u} \mathrm{BrPt}$ - vistinu stari i prêstari $\cdot i$ kvekaûca čeda ispueni biše; $\mathrm{u} \mathrm{BrVO}-$ ot roda $\cdot i$ priêtelb spuždeniê; u $\mathrm{BrBrit}_{\mathrm{i}} \mathrm{BrBer}_{2}-i$ v' manastirb pon'tinen 'ski navlaĉ'no naporučenb bistb.

Nekoliko je primjera teksta koji se u nekim brevijarima pojavljuje, a u nekima izostaje. Katkad je riječ o dodavanju pojedine riječi: u $\mathrm{BrBer}_{2}-n a$ d(a)nь $s(v e) t$ (a) go tombsa; u BrBrit - na d(a)n's(ve)t(a) go tom(a)sa; u BrVO - na sv(e)t(a)go tomasa d(a)n'. $\mathrm{U} \mathrm{BrBer}_{2} \mathrm{i}$ BrBrit dodan je koordinirani pridjev ugodan: vzmožans $i$ ugod(a)nь BrBer $_{2}$ vzmožan' $i$ ugodanь BrBrit, pri čemu se odstupa od latinskoga jer je u latinskome samo pridjev devotus. U tim je brevijarima dodan i pridjev: nečtovan 'i vêlici $\mathrm{BrBer}_{2}$ nečtovan ' $i$ velicê BrBrit, i zamjenica: b(la)ž(e)ni že tom(a)sb izvoli ustanov(i)tit(i) se · ustupiti se zlobi ihь $\operatorname{BrBer}_{2}$ b(la)ž(e)ni že tomasb · izvoli us'tanovititi se $i$ ustupiti se z'lobê ihь BrBrit. U BrN ${ }_{2}$ i u $\mathrm{BrVat}_{19}$ dodaje se negacija: pos'toêše ne trepetanb, u $\mathrm{BrN}_{1}$ - pridjev dobar: dobri ćinomb, u BrPm - imenica bog: bis $\left(t_{b}\right) \mathrm{b}(\mathrm{og}) \mathrm{u}, \mathrm{u}$

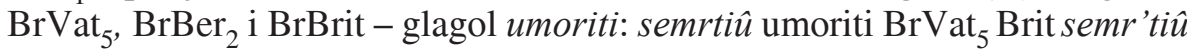
umoriti $\mathrm{BrBer}_{2}$, u $\mathrm{BrVat}_{19}$ - posvojni pridjev: drugi tomasovi $\cdot i$.

Rjeđe se dodaju i dijelovi rečenica. $\mathrm{U} \mathrm{BrN}_{1}$ i u BrVin dodaje se dio rečenice u početnome dijelu teksta: $v \mathrm{~d}(\mathrm{a}) \mathrm{nb} s(v e) t(a)$ go tomasa vsa ča manka iĉi 
ot ednoga $\mathrm{b}(\mathrm{i}) \mathrm{sk}(\mathrm{u}) \mathrm{pa} \cdot \check{\mathrm{c}}($ tenie $) \cdot \mathrm{BrN}_{1} n($ a) d(a)nь $s$ (veta) go tomasa vsa ka mankaû $\cdot$ iĉi $\cdots \mathrm{a} \cdot \mathrm{m}(\mathrm{u}) \mathrm{c}(\mathrm{eni}) \mathrm{ka} \mathrm{BrVin}$. Dio se rečenice dodaje i u BrBer${ }_{2}, \mathrm{BrPt}$ i BrBrit: blagodet'nims dêeniems · i bêz' prestaniê ugaždae b(og)u va vsehь ti že $\mathrm{g}(\mathrm{ospod}) \mathrm{i} \mathrm{p}(\mathrm{o}) \mathrm{m}(\mathrm{i}) l u i \cdot \mathrm{BrBer}_{2}$ bl(a)g(o)detnim dêeniemb i b(e)s prêstani ugaždae ti že g(ospod)i $\mathrm{p}(\mathrm{o}) \mathrm{m}(\mathrm{i}) \mathrm{lui} \mathrm{n}(\mathrm{a}) \mathrm{sb} \mathrm{b}(\mathrm{og}) \mathrm{u} \mathrm{h}(\mathrm{vali}) \mathrm{BrPt}$ blagodêtnimb $\cdot$ dêêniemb $\cdot i$ bez prestaniê ugaždae $\mathrm{b}(\mathrm{og}) \mathrm{u}$ va v'sêhь BrBrit.

\section{ODNOS LATINSKOGA TEKSTA I PRIJEVODA}

U hrvatskoglagoljskim brevijarima riječ je o skraćenoj inačici Službe u čast sv. Tomi Becketu koja prati prva dva i polovicu trećega čitanja latinske službe Sarum, tj. službe iz BrSar - do Becketova izgnanstva i susreta s francuskim kraljem. Hrvatskoglagoljski tekst nastao je vrlo vjernim prevođenjem. U prijevodu se uvodni dio koji najavljuje tekst službe razlikuje od utvrđenoga latinskog predloška, a ostatak teksta vjerno prati latinski izvornik. Kao primjer podudarnosti hrvatskoglagoljskoga prijevoda s latinskim tekstom, usporedno se navodi kratak dio početka teksta.

Početak je latinskoga teksta:

Gloriosi martyris Thomae, fratres carissimi, natalem celebrantes, quia totius vitae et conversationis eius insignia recolere non sufficimus, passionis eius modum causamque succinctus sermo percurrat.

Početak je hrvatskoglagoljskoga teksta:

slavnago mučenika tomasa bratie m(i)lêiša $\cdot$ rožd(a)stvo čtuĉe $\cdot \hat{k} k o$ vsego života ego prêbivaniê v znameniêh' čisti ne dovlêemo muk' i stvari ego $n(i) n e \cdot$ prêpoêsan'sl(o)v(o)m' prêd'teče $\left(\mathrm{BrVb}_{1} 42 \mathrm{c}\right)$.

Nekoliko je dijelova rečenica ili sintagma koje se ne prevode. Ni u jednome se brevijaru ne navodi prijevod dijela latinske rečenice u kojemu se spominju žene koje leže u trudovima: vagientes in cunis, et mulieres in puerperio decubantes, in exilium acti sunt $: i$ kvekaûca čeda ispueni biše $\left(\mathrm{BrVb}_{1}\right.$ 43a). Vjerojatno je riječ o tome da je prevoditelj sliku žene pri porodu smatrao nepriličnom. U prijevodu su u nekim slučajevima ispuštene i pojedine riječi: Negavit constanter archiepiscopus : ne zataûe krêp'ko ( $\left.\mathrm{BrVb}_{1} 42 \mathrm{~d}\right)$, damna, contumelias et opprobria parentum, et amicorum proscriptionem : škodi i sramoti i ponošeniê BrVO. U BrBrit i BrBer ${ }_{2}$ izostavljen je dio rečenice u kojemu se spominje odlazak u samostan: et in monasterio Pontiniacensi studiose commendatus : $i$ v manastir' pon'tiniêski navlaĉ 'no naporučen' bisi ·čtt(enie) $\left(\mathrm{BrVb}_{1} 43 \mathrm{a}\right)$. 


\section{PREVODITELJSKI POSTUPCI}

Pri prevođenju s latinskoga na hrvatski crkvenoslavenski jezik prevoditelji nastoje što vjernije pratiti latinski predložak. Međutim, pojedini oblici i strukture u latinskome i hrvatskome crkvenoslavenskom nemaju istu raspodjelu ili ulogu. Osobit su problem pri prevođenju s latinskoga na hrvatski konstrukcije, zavisne rečenice i oblici koji ne postoje u hrvatskome crkvenoslavenskom.

Latinski particip prezenta uglavnom se prevodi participom prezenta aktivnim, koji mu je istovrijednica u hrvatskome crkvenoslavenskom: celebrantes : čtuce ( $\left(\mathrm{BrVb}_{1} 42 \mathrm{c}\right)$; studens : nastoe $\left(\mathrm{BrVb}_{1} 42 \mathrm{c}\right)$; sciens : ugaždae $\left(\mathrm{BrVb}_{1}\right.$ $42 \mathrm{c})$; vagientes in cunis : $i$ kvekâ̂ca čeda $\left(\mathrm{BrVb}_{1} 43 \mathrm{a}\right)$; Timens autem beatus Thomas occasione sui : boe že se b(la)ž(e)ni tomas' prirokom' svoim' ' $\mathrm{BrVb}_{1}$ 43b). Nekoliko je, međutim, slučajeva u kojima se particip prezenta aktivnoga prevodi prošlim participom: sciens : vidêv $\left(\mathrm{BrVb}_{1} 42 \mathrm{c}\right)$; Audiens ergo rex immobilem eius constantiam: slišav že c (êsa)rb utvr'ždenie ego krêposti $\left(\mathrm{BrVb}_{1}\right.$ 43b). Riječ je o participima glagola scio, 4. i audio, 4., koji se i inače često u hrvatskoglagoljskim tekstovima prevode prošlim participima, najčešće jer i u latinskome neprototipno ne označavaju istodobnu radnju, ${ }^{13}$ nego radnju koja se doživljava kao trenutačna, ali s posljedicama ${ }^{14}$ ili kratkotrajni događaj. Rjeđi su primjeri u kojima se particip prevodi finitnim oblikom: manifestam in eis asserens : očito v nih' g(lago)laše ( $\left.\mathrm{BrVb}_{1} 42 \mathrm{~d}\right)$; Sed vir Dei manum suam mittens ad fortia : nь mužb b(o)ži ruku svoû posla na krêpkaê (BrVb $\left.{ }_{1} 43 a\right)$. Jedan je primjer u kojemu se particip prevodi pridjevom otainim': Et sub vestibus clericalis honestatis habitum celans monachalem : i pod rizami gospod'skimi smêrenim ' abitom' otainim' koludr'skim' ( $\left.\mathrm{BrVb}_{1} 42 \mathrm{c}\right)$. Particip se prezenta ni u jednome slučaju ne prevodi odnosnom rečenicom, što je danas najčešći način prevođenja participa. Particip prošli uglavnom se prevodi pasivnim participom prošlim: Actus ergo in exilium a domino papa Alexandro : zaslan' ubo s neč'stiû · $i$ ot g(ospodin) a papi tretago alekbsan'dra $\left(\mathrm{BrVb}_{1} 43 \mathrm{a}\right)$; Ut vel compassionis gladio totiens confossus : da bolêzniû meča tolikokrat' proboden' $\left(\mathrm{BrVb}_{1} 43 \mathrm{a}\right)$; nulla prorsus fractus aut immutatus iniuria : niedinô̂ skrušen' ili izmênen' sramotoû $\left(\mathrm{BrVb}_{1} 43 \mathrm{~b}\right)$; Consecratus enim repente mutatus est in virum alium : Posveĉen' že naglo · i prêmênen' bis(tb) v muža drugago $\left(\mathrm{BrVb}_{1} 42 \mathrm{c}\right)$. Particip koji je dio prijedložnoga izraza nije doslovno preveden: ita et post susceptum pastoris officium : i tako mučiti se načet' pastir' 'činom' $\left(\mathrm{BrVb}_{1} 42 \mathrm{c}\right)$.

\footnotetext{
${ }^{13}$ GORTAN; GORSKI; PAUŠ 2005: 241.

${ }^{14}$ Slično prezentu perfekta u engleskome, tj. ima značenje čuo sam pa sad znam ili vidio sam pa sad znam.
} 
Ablativ apsolutni najčešće se prevodi finitnim rečenicama s veznikom $i$ ili bez njega: Tandem sibi morte intentata : i potom' iskahu i semr'tiû ( $\mathrm{BrVb}_{1}$ 42d); ostenso sibi caelitus inditio quod ad ecclesiam suam rediturus esset cum gloria et per martyrii palmam migraturum ad dominum : skazana eтu bisi s n(e)b(e)se zapovêd' · êko k' cr(ê)kvi svoei vratiti se imêse s'sl(a)vồ · $i$ palmô̂ muki prêiti $k b$ g(ospode)vê $\left(\mathrm{BrVb}_{1} 43 \mathrm{~b}\right)$; Unde gravi quaestione super iure ecclesiastico et regni consuetudinibus inter ipsum et regem Anglorum exorta : Otnûdêže usilna rasprı o pravdê cr(ê)kvenoi $\cdot$ ot zakona vladaniê meždû im' - i c(êsa)rem' ot an 'glie v'zdviže se $\left(\mathrm{BrVb}_{1} 42 \mathrm{~d}\right)$. Ablativ apsolutni et excogitato novo supplicii genere : iz' razmisla novoe strasti roda $\left(\mathrm{BrVb}_{1}\right.$ 43a) prevoditelj prepoznaje kao prijedložni izraz ex cogitato. Ablativ apsolutni prevodi se i instrumentalom apsolutnim: directis per abbates quosdam cisterciensis ordinis ad capitulum generale litteris comminatoriis : poslanimi listi po eterêh' opatêh' čisterien 'skago reda · na kapituli vsego sbora listi prêtbbenimi $\left(\mathrm{BrVb}_{1} 43 \mathrm{~b}\right)^{15}$ ili imenskom skupinom u instrumentalu: tactis sacrosanctis : kosneniem's(ve)tos(ve)tihb (BrVb $43 \mathrm{a})$. Ablativ apsolutni prevodi se i participom u nominativu množine, a imenica postaje objektom: mari transito : more prêšbdše ( $\left.\mathrm{BrVb}_{1} 43 \mathrm{a}\right)$. Takav je prijevod i ablativa apsolutnoga coadunto consilio : $i$ stvorše vêce $\left(\mathrm{BrVb}_{1} 42 \mathrm{~d}\right)$. $\mathrm{U}$ nekim se brevijarima umjesto stvorše pojavljuje oblik stvoriše, vjerojatno kao odraz pogrešnoga čitanja prepisivača.

Nominativ s infinitivom pojavljuje se dvaput i u obama je primjerima glavni glagol u pasivu glagol video, 2. Taj je glagol u prvome primjeru u većini brevijara preveden prilogom očito, a u $\mathrm{BrVb}_{1}$ na tome mjestu stoji oblik učiti: et personalis videbatur persecutio : $i$ v têlê učiti (!) progonahu $\left(\mathrm{BrVb}_{1}\right.$ 42d). Očito je riječ o pogrešci pisara, ali moguće je da je ona motivirana činjenicom da je u drugome primjeru nominativa s infinitivom učiti prijevod latinskoga infinitiva docere dok je glavni glagol preveden povratnim oblikom glagola vidêti: ut omnes coexules suos docere videretur : da drugi svoe učiti vidêl' se bi $\left(\mathrm{BrVb}_{1} 43 \mathrm{~b}\right)$.

Gerundiv koji zamjenjuje gerund prevodi se glagolskom imenicom: in rebus gerendis $: v$ stvareh' dêeniê $\left(\mathrm{BrVb}_{1} 42 \mathrm{c}\right)$. Perifrastična konjugacija pasivna prevodi se tako da se gerundiv prevodi infinitivom, ali bez glagola biti: cedendum censuit esse malitiae : izvoli ustanoviti · ustupiti izvoli zlobê $\left(\mathrm{BrVb}_{1}\right.$ 42d-43a).

Veznik quia, koji se inače razmjerno često pojavljuje i kao veznik izričnih rečenica, u ovome se tekstu pojavljuje isključivo kao veznik uzročnih re-

\footnotetext{
${ }^{15} \mathrm{U}$ tome primjeru prevoditelj dvaput ponavlja riječ listi vjerojatno zato da dužina rečenice ne bi omela razumijevanje.
} 
čenica i prevodi se veznikom êko, koji je njegova prototipna istovrijednica i kad je riječ o uzročnome i kad je riječ o izričnome značenju: quia totius vite et conversationis eius insignia recolere non sufficimus : êko vsego života ego prêbivaniê $v$ znameniêh' čisti ne dovlêemo $\left(\mathrm{BrVb}_{1} 42 \mathrm{c} 9\right)$; quia causa ecclesiae nondum plene innotuerat, et personalis videbatur persecutio : êko stvar' cr(ê)kvena ne oĉe plbno bêše znana · iv têlê učiti (!) progonahu (BrVb 42d). Rečenice uvedene veznikom quia stoje s indikativom koji se prevodi doslovno.

Rečenice uvedene akuzativom množine odnosne zamjenice quas prevode se jedanput doslovno rečenicom s veznikom eže: quas publica sibi potestas usurpaverat : eže emu obcina oblast' vzela bêše ( $\left.\mathrm{BrVb}_{1} 42 \mathrm{~d}\right)$, a drugi put rečenicom s veznikom êko: quas idem rex tam archiepiscopi quam suffraganeorum suorum scripto roborari pertinaciter exegit : êko tbžde c(êsa)rb $i$ arhib(i)skupi s družinoû svoê̂ pismom' utvrbditi tvr'do steza $\left(\mathrm{BrVb}_{1} 42 \mathrm{~d}\right)$. Rečenica uvedena veznikom quotquot prevodi se rečenicom s veznikom elikože: Quotquot autem discretionis annos attigerant : elikože im 'vzrastom' lêti pristoêhu $\left(\mathrm{BrVb}_{1} 43 \mathrm{a}\right)$.

Izrične rečenice, koje su karakteristične za srednjovjekovni latinski, ${ }^{16}$ uvedene su veznicima quod i quoniam. Jedanput se rečenica uvedena veznikom quod prevodi rečenicom uvedenom veznikom $d a$, koji je i danas prototipni izrični veznik: iurare compulsi sunt, quod mari transito, statim Cantuariensi archiepiscopo se praesentarent $:$ kleti se nuždeni bêhu $\cdot$ da more prêšbďse $\cdot$ abie kanterêiskomu arhiepiskupu prikažut se $\left(\mathrm{BrVb}_{1} 43 \mathrm{a}\right)$. Druga izrična rečenica uvedena veznikom quod i rečenica uvedena veznikom quid prevode se rečenicama uvedenima veznikom êko: Tanta namque fuit confessoris Christi constantia ut omnes coexules suos docere videretur, quid omne solum forti patria est. : tolika ubo bê krêpost' isp(o)vêdnika h(rbsto)va · da drugi svoe učiti vidêl' se bi · êko vsakomu krêpkomu z(e)mla dêdina est' ( $\left.\mathrm{BrVb}_{1} 43 \mathrm{~b}\right)$; ostenso sibi caelitus inditio quod ad ecclesiam suam rediturus esset cum gloria et per martyrii palmam migraturum ad Dominum : skazana emu bisi s n(e)b(e)se zapovêd' ·êko k' cr(ê)kvi svoei vratiti se imêše s' sl(a)vồ · i palmô̂ muki prêiti kb g(ospode)vê ( $\left.\mathrm{BrVb}_{1} 43 \mathrm{~b}\right)$. Pri prevođenju zavisnih rečenica s latinskoga na hrvatski crkvenoslavenski osobit je problem prevođenje konjunktivnih oblika. Konjunktiv imperfekta u hrvatskoglagoljskim tekstovima često se prevodi kondicionalom. Međutim, u izričnoj se rečenici konjunktiv praesentarent prevodi indikativom, $\mathrm{i}$ to svršenim prezentom: prikažut se $\left(\mathrm{BrVb}_{1} 43 \mathrm{a}\right)$. Konjunktivi imperfekta perifrastične konjugacije aktivne rediturus esset... migraturum prevode se infinitivom uz imperfekt glagola imati: vratiti se

$\overline{16}$ V. CUZZOLIN 1994; CUZZOLIN 2003.a; CUZZOLIN 2003.b. 
imêše... prêiti $\left(\mathrm{BrVb}_{1} 43 \mathrm{~b}\right)$, što je čest način prevođenja perifrastične konjugacije aktivne i participa futura koji se pojavljuje kao njezin sastavni dio.

$\mathrm{U}$ posljedičnim rečenicama s veznikom $u t$ taj se veznik prevodi veznikom da, svojom prototipnom istovrijednicom: Ut vel compassionis gladio totiens confossus, conceptum animi rigorem ad regis voluntatem inflecteret. : $d a$ bolêzniû meča tolikokrat' proboden' začetiem' $d(u)$ ši usiliê $k$ ' c(êsa)ru volu priklonil bi $\left(\mathrm{BrVb}_{1} 43 \mathrm{a}\right)$; Tanta namque fuit confessoris Christi constantia ut omnes coexules suos docere videretur, quid omne solum forti patria est. : tolika ubo bê krêpost' isp(o)vêdnika h(rbsto)va · da drugi svoe uniti vidêl' se bi . êko vsakomu krêpkomu z(e)mla dêdina est' $\left(\mathrm{BrVb}_{1} 43 \mathrm{~b}\right)$. U tim se primjerima konjunktiv imperfekta prevodi kondicionalom.

Jedna je vremenska rečenica, i to uvedena veznikom antequam s konjunktivom imperfekta. Ta je rečenica prevedena rečenicom s vezničkim sredstvom prežde neže i finitnim glagolom, što je tipično za prevođenje toga tipa rečenica: Sed antequam inde progrederetur : no prêžde neže izide $\cdot b(o) z ̌ i m b$ êvleniem' ukrêplen' bisi ( $\left.\mathrm{BrVb}_{1} 43 \mathrm{~b}\right)$.

U latinskome je predlošku nekoliko akuzativa s infinitivom, često bez infinitiva glagola sum, esse, fui. Kad je riječ o rečenicama u kojima se izriče zapovijed, konstrukcija je prevedena doslovno, tj. akuzativ je preveden akuzativom, a infinitiv infinitivom: carnem prorsus coegit servire spiritui : têlo s'vsêma udruči rabotati d(u)hom' $\left(\mathrm{BrVb}_{1} 42 \mathrm{c}\right)$; quas idem rex tam archiepiscopi quam suffraganeorum suorum scripto roborari pertinaciter exegit : êko tbžde c(êsa)rb i arhib(i)skupi s družinoû svoêิ pismom' utvrbditi tvr'do steza $\left(\mathrm{BrVb}_{1} 42 \mathrm{~d}\right)$; manifestam in eis asserens libertatis ecclesiasticae subversionem : krêp'ko i očito v nih' g(lago)laše $\left(\mathrm{BrVb}_{1} 42 \mathrm{~d}\right)$. I kad nije riječ o izricanju zapovijedi, akuzativ s infinitivom katkad se prevodi doslovno: eum a Pontiniaco perturbare curavit: ot pon 'ciên'skago manastira smutiti ga pećalova $\left(\mathrm{BrVb}_{1} 43 \mathrm{~b}\right)$. Osim toga, ta se konstrukcija prevodi tako da se glavni glagol u participu prevodi participski, a akuzativi se prevode nominativima, ali bez glagola biti i bez veznika koji uvodi surečenicu: Sciensque se cultorem positum in agro Dominico, in vinea custodem, pastorem in caulis : vidêv se dêlatel' postavlen' na nivê g(ospod)ni · vb vinogradê stražb 'pbstir' v' ogradê $\left(\mathrm{BrVb}_{1} 42 \mathrm{~d}\right)$. $\mathrm{U}$ jednoj je rečenici u latinskome unutar akuzativa s infinitivom $\mathrm{i}$ perifrastična konjugacija pasivna. U tome primjeru prevoditelj vjerojatno nije u potpunosti razumio latinski tekst. U prijevodu se pojavljuje dvaput glagol izvoli i pojavljuju se dva infinitiva: cedendum censuit esse malitiae : izvoli ustanoviti $\cdot$ ustupiti izvoli zlobê $\left(\mathrm{BrVb}_{1} 42 \mathrm{~d}\right)$.

Jedan je primjer konjunktiva u nezavisnoj rečenici. Riječ je o konjunktivu prezenta koji se prevodi indikativom prezenta: passionis eius modum cau- 
samque succinctus sermo percurrat : muk' $i$ stvari ego n(i)ne ' prêpoêsan' sl(o)v(o)m' prêd'teče $\left(\mathrm{BrVb}_{1} 42 \mathrm{c}\right)$.

Red riječi uglavnom vrlo vjerno prati latinski predložak. Odstupanja su najčešće u redoslijedu sastavnica u imenskoj skupini: passionis eius modum causamque: muk' istvari ego $\left(\mathrm{BrVb}_{1} 42 \mathrm{c}\right)$; vitae et conversationis eius insignia : života ego prêbivaniê v znameniêh' $\left(\mathrm{BrVb}_{1} 42 \mathrm{c}\right)$; iura et dignitates ecclesiae : pravdi cr(ê)kvenago dostoêniê $\left(\mathrm{BrVb}_{1} 42 \mathrm{~d}\right)$; publica sibi potestas : obcina oblast' (BrVb $42 \mathrm{~d})$; confessoris Christi constantia : krêpost' isp(o)vêdnika h(rbsto)va $\left(\mathrm{BrVb}_{1} 43 \mathrm{~b}\right)$; comminatoriis litteris : listi prêtıbenimi $\left(\mathrm{BrVb}_{1} 43 \mathrm{~b}\right)$. Samo je jedan primjer u kojemu se zamjenjuje redoslijed sastavnica u ablativu apsolutnome: sibi morte intentata : iskahu i semr'tiû (BrVb $142 \mathrm{~d})$. Jedini je primjer u kojemu se glagol koji nije na posljednjemu mjestu u rečenici prevodi na posljednjemu mjestu: Thomae proscribitur cognatio : tomasovo bližič stvo izbgnaše $\left(\mathrm{BrVb}_{1} 43 \mathrm{a}\right)$. Zamjenjuje se redoslijed infinitiva i objekta: imminere dispendium : semr'ti približaniê $\left(\mathrm{BrVb}_{1} 43 \mathrm{~b}\right)$. $\mathrm{U}$ jednome se primjeru zamjenjuje redoslijed participa glagola i povratne zamjenice: sibi creditum : prêdanago eтu $\left(\mathrm{BrVb}_{1} 42 \mathrm{~d}\right)$. U primjeru omne solum forti patria est : vsakomu krêpkomu z(e)mla dêdina est' $\left(\mathrm{BrVb}_{1} 43 \mathrm{~b}\right)$ promijenjen je redoslijed riječi z(e)mla (lat. solum) i krêpkomu (lat. forti). U tome primjeru prevoditelj pogrešno povezuje pridjev omne s forti umjesto sa solum. Zamjenica koja je objekt glagola perturbare prevodi se nakon glagola: eum a Pontiniaco perturbare curavit : ot pon'ciên'skago manastira smutiti ga pečalova $\left(\mathrm{BrVb}_{1} 43 \mathrm{~b}\right)$.

U tekstovima ima i nešto pogrešaka pri prepisivanju. Neke su od tih pogrešaka navedene i u odlomku o leksičkim razlikama te su označene i u transliteraciji. Od ostalih pogrešaka zanimljiv je primjer iz BrVO u kojemu prepisivač riječ razbora prepisuje kao rabora zbora: sine delectu conditionis aut fortunae : bez' rabora (!) zbora svêdêniê ili gnêva dostoini.

\section{ZAKLJUČAK}

Tekst liturgijske Službe u čast sv. Tomi Becketu nalazi se u dvadeset i jednome hrvatskoglagoljskom brevijaru u dijelu Proprium de tempore. Tekst je nastao prijevodom latinske službe Sarum, tj. službe iz Sarumskoga brevijara (BrSar). Riječ je o istome prijevodu, a tekstovi u različitim brevijarima razlikuju se uglavnom fonološki i morfološki te rjeđe leksički. Tekst prati prva dva i pol čitanja latinskoga brevijara. Od tekstova iz ostalih brevijara duljinom znatnije odstupaju kraći tekstovi u BrOxf, BrPm i BrVat ${ }_{10}$. Od većine brevijarskih tekstova nešto je kraći i tekst u BrVat ${ }_{19}$, dok su tekstovi u BrBar, BrMav i BrBroz tek neznatno kraći od ostalih. Fonološke i morfološke razlike 
nisu važne za podrijetlo teksta. One govore o mladosti/starosti prijepisa i o stavu prepisivača prema normi. Nisu posebno važne ni leksičke razlike. Pojedini brevijari ispuštaju i dodaju pojedine riječi u tekstu. Rijetko se tekstovi razlikuju time što imaju pojedini dio (dio rečenice ili cijelu rečenicu) koji drugi nemaju. Prijevod teksta vrlo vjerno prati latinski predložak. Nekoliko je dijelova rečenica ili sintagma koje se ne prevode. Međutim, pojedini oblici i strukture u latinskome i hrvatskome crkvenoslavenskom nemaju istu raspodjelu ili ulogu. Osobit su problem pri prevođenju s latinskoga na hrvatski konstrukcije, zavisne rečenice i oblici koji ne postoje u hrvatskome crkvenoslavenskom. Ablativ apsolutni najčešće se prevodi finitnim rečenicama s veznikom $i$ ili bez njega, međutim, prevodi se i instrumentalom apsolutnim ili imenskom skupinom $\mathrm{u}$ instrumentalu. Nominativ $\mathrm{s}$ infinitivom pojavljuje se dvaput uveden glagolom video, 2. u pasivu. U jednoj se rečenici prevodi prilogom očito, a u drugome primjeru povratnim oblikom glagola vidêti. Gerundiv koji zamjenjuje gerund prevodi se glagolskom imenicom. Veznik quia pojavljuje se isključivo kao veznik uzročnih rečenica i prevodi se veznikom êko. Pri prevođenju zavisnih rečenica s latinskoga na hrvatski crkvenoslavenski osobit je problem prevođenje konjunktivnih oblika. Konjunktiv imperfekta u hrvatskoglagoljskim tekstovima često se prevodi kondicionalom, međutim, u izričnoj se rečenici prevodi indikativom, i to svršenim prezentom. Konjunktivi imperfekta perifrastične konjugacije aktivne prevode se infinitivom uz imperfekt glagola imati, što je čest način prevođenja perifrastične konjugacije aktivne i participa futura koji se pojavljuje kao njezin sastavni dio. U latinskome je predlošku nekoliko akuzativa s infinitivom, često bez infinitiva glagola sum, esse, fui. Kad je riječ o rečenicama u kojima se izriče zapovijed, konstrukcija je prevedena doslovno. I kad nije riječ o izricanju zapovijedi, akuzativ s infinitivom katkad se prevodi doslovno. Osim toga, ta se konstrukcija prevodi tako da se glavni glagol u participu prevodi participski, a akuzativi se prevode nominativima, ali bez glagola biti i bez veznika koji uvodi surečenicu. Jedan primjer konjunktiva prezenta u nezavisnoj rečenici preveden je indikativom prezenta. Red riječi uglavnom vrlo vjerno prati latinski predložak. Odstupanja su najčešće u redoslijedu sastavnica u imenskoj skupini.

Budući da je riječ o svetcu s kraja 12. st., prijevod nije mogao biti stariji od početka 13. st. Najstariji je brevijar u kojemu je sačuvan tekst $\mathrm{BrVb}_{1}$ s kraja 13. ili početka 14. st., dakle, tekst je morao biti preveden prije toga. Zbog toga je vjerojatno da je tekst preveden u 13. st., najvjerojatnije u njegovoj drugoj polovici. Na to upućuje i pojava instrumentala apsolutnih, a ne dativa apsolutnih. Tekst je najvjerojatnije preveden nakon otpisa pape Inocenta IV. senjskomu biskupu Filipu i odobrenja staroslavenskoga bogoslužja, kad je provedena franjevačka reforma misala i brevijara te revizija hrvatskogla- 
goljskih liturgijskih tekstova. ${ }^{17}$ Prevoditelj vrlo vjerno prevodi latinski tekst, ali vjerno prenesene latinske strukture ne znače da prevoditelj nije znao latinski, nego su odraz stava prema prevođenju i ustaljenih prijevodnih praksa. U tekstu nisu potvrđene veće pogreške koje bi ukazivale na to da prevoditelj tekst ne razumije, osim pri prevođenju perifrastične konjugacije pasivne koju hrvatskoglagoljski prevoditelji često ne prepoznaju.

\section{TEKST}

Kao osnovni je tekst uzet najstariji tekst Službe u čast sv. Tomi Becketu iz I. vrbničkog brevijara $\left(\mathrm{Vb}_{1} 42 \mathrm{~b}-43 \mathrm{~b}\right)$. Razlike u drugim brevijarima navode se u bilješkama. Navode se samo tekstološki relevantne razlike, ne navode se različito pokraćene riječi. Pojedina su slova prenesena u skladu s načelima u novijim izdanjima Staroslavenskoga instituta: slovo $\mathrm{B}$ transliterira se kao $\hat{e}$, slovo Il kao $\hat{u}$, slovo w $\mathrm{u}$ kao $\hat{c}$, slovo I (štapić) kao b, a slovo ' (apostrof) kao'. Oznaka za početak službe prenesena je kao $\odot$. Kraćene riječi razrješuju se u okruglim zagradama ( ). Nečitke riječi i slova rekonstruiraju se u uglatim zagradama [ ]. Riječi i slova koji su u izvorniku ispušteni navode se u šiljatim zagradama \langle\rangle . Ispuštanje pojedinoga mjesta označava se oznakom om. Nečitka mjesta bilježe se oznakom illeg. Završetak teksta koji se razlikuje od završetka tekstova u drugim brevijarima označava se oznakom finis.

$\overline{17}$ O reformi hrvatskoglagoljskih tekstova u 13. st. usp.: CORIN 1997; HAMM 1953: 30-31; MAREŠ 1985; TANDARIĆ 1993: 72, 310-311; MIHALJEVIĆ 2009; VAJS 1903: 66. 
(C)

ot $^{1} \mathrm{~s}(\mathrm{ve}) \mathrm{t}(\mathrm{a}) \mathrm{go}^{2}$ tomasa $^{3} \cdot \operatorname{an}(\text { tifon })^{4}$ i b(e)rš $(\mathrm{b})^{5}$ iĉi $^{6} \cdot \mathrm{a} \cdot(=1)^{7}$

mučenika b(i)sk(u)pa ${ }^{8} \cdot \operatorname{or}(\mathrm{a}) \mathrm{c}(\mathrm{iê})^{9}$

$\mathrm{B}(\mathrm{ož}) \mathrm{e}^{10} \mathrm{za}^{11}$ negože $\mathrm{e}^{12} \mathrm{cr}(\hat{\mathrm{e}}) \mathrm{k}(\mathrm{a}) \mathrm{vb}^{13} \mathrm{sl}(\mathrm{a}) \mathrm{vni} \mathrm{a}-$

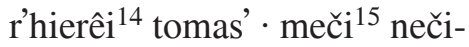

stivih' $^{16}$ obleža $^{17} \cdot$ podai

$42 \mathrm{c}$

m(o)l(imb) te $\cdot$ da vsi iže ${ }^{18}$ ego $^{19}$ proset'

pomoc $\hat{c}^{\prime 20} .21$ prošeniê svoego sp(a)seniê ${ }^{22}$ da postignut' ${ }^{23}$ svrıšen-

\footnotetext{
${ }_{1}^{1}$ ot ] na Bar Broz Oxf om. Ber ${ }_{2}$ Vat $_{19}$ Vat $_{5}$ Vin n(a) Pm Brit

${ }^{2}$ s(ve)t(a)go ] s(ve)tomu Vin

3 tomasa ] tomasa m(u)č(enika) Pm tomasu Vin

${ }^{4}$ an(tifonь) ] an(tifon)a Vat ${ }_{5}$ a(ntifo)ni Brit Pm

${ }^{5}$ i b(e)rš(b) ] i b(e)rši Ber ${ }_{2}$ Bar Mav Broz Brit om. Vat ${ }_{5}$ b(e)rš(b) Pm

${ }^{6}$ iĉi ] om. Brit

${ }^{7}$ a ] ot Ber 2 VO Rom $N_{1}$ Vat $_{5} \mathrm{~N}_{2}$ Drag Vat ${ }_{10}$ Brit ot a Vat ${ }_{19}$ ot ednoga Vin

${ }^{8}$ b(i)sk(u)pa ] om. Vat ${ }_{19}$ i b(i)sk(u)pa Oxf $\cdot$ ki e biskupь $\cdot$ a se $\cdot$ Drag

$\left.{ }^{9} \operatorname{or}(\mathrm{a}) \mathrm{c}(\mathrm{iê})\right]$ or(a)cii Mav om. Ber $_{2} \mathrm{~N}_{1} \operatorname{Oxf~N}_{2} \mathrm{Pad}$

${ }^{10}$ b(ož)e ] b(og)b VO N

11 za ] z' Mav

12 negože ] koga Broz

$13 \operatorname{cr}(\hat{\mathrm{e}}) \mathrm{k}(\mathrm{a}) \mathrm{vb}] \operatorname{cr}(\hat{\mathrm{e}}) \mathrm{kvi} \mathrm{N}_{1}$

${ }^{14}$ ar'hierêi ] ar'hierêi tvoi $\mathrm{Ber}_{2}$ Brit arhierêi tvoi VO arhierei Met

15 meči ] mači Pm

16 meči nečistivih' ] meči stivih' (!) Pad

${ }^{17}$ obleža ] uspê VO $\mathrm{N}_{1}$ Pm Vin Met ne uboê se Mav Pad oblêža Rom us'pê Vat ${ }_{19}$ Vat $_{5} \mathrm{~N}_{2}$ Vat $_{10}$ ubêža Oxf

18 iže ] ki Mav Broz

19 ego ] om. Vin

${ }^{20}$ proset' pomoĉ́ ] prosetь pomoĉi Bar VO Broz Drag Vin Brit pomoĉi prosetь Vat ${ }_{19} \mathrm{Vat}_{5} \mathrm{~N}_{2}$ Vat $_{10}$ pomoĉi proset' Met

${ }^{21}$ ego proset' pomoĉ' · prosetb ego pom(o)ĉi Mav prosetı ego pomoĉi $\mathrm{N}_{1}$

22 prošeniê svoego sp(a)seniê ] prošenie svoego sp(a)s(e)niê Bar Broz $\mathrm{Pm} \mathrm{N}_{2}$ sp(a)s(e)niê svoego proš(e)nie Mav prošenie svoego svoego (!) sp(a)s(e)niê Rom prošenie s'voego sp(a)s(e)niê Vat $_{19}$ prošenie svoego sp(a)seniê Vin Drag prošenie s'voego s'p(a)s(e)niê Oxf prošeniê svoego i sp(a)seniê Brit

${ }^{23}$ postignut'] postignitь $\mathrm{Vat}_{10}$
} 


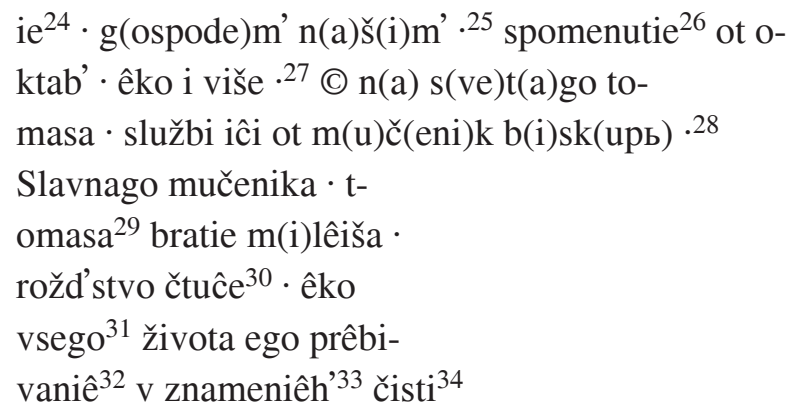

\footnotetext{
${ }^{24}$ svr'šenie ] svršeniê Met isvršenie Brit

${ }^{25} \mathrm{~g}$ (ospode)m' n(a)š(i)m' · ] i budi Ber ${ }_{2} \cdot \mathrm{i}$ b(u)di v Bar $\mathrm{N}_{1}$ Broz om. Mav Rom Drag k' ûtri Vat ${ }_{19}$ - $\mathrm{i}$ budi Vat ${ }_{5}$ Vin i budi v' $\mathrm{N}_{2} \mathrm{~g}$ (ospode)mь i budi Met i budi v Brit g(ospodem)ь Pm

${ }^{26}$ spomenutie ] v'spom(e)nutie Ber $_{2} \operatorname{sp}(\mathrm{o}) \mathrm{m}(\mathrm{in}) \mathrm{b}$ Bar VO Broz spominь Mav $\mathrm{N}_{1}$ om. Vat ${ }_{19}$ spomeni Pm pomenutie $\mathrm{N}_{2}$ spom'nь Met

${ }^{27}$ ot oktab' - êko i više · ] okt(a)vь Bar budi ot okt(a)bь êko i više $\cdot$ VO ot okt(a)bь Mav $\mathrm{N}_{1}$ $\mathrm{N}_{2}$ okt(a)vi Broz om. Vat ${ }_{19}$ ot oktabь vsêhь êk(o)že r(e)č(e)no est' v(i)̌̌e $\cdot$ čt(eni)e $\cdot V^{2} t_{5}$ ot okt(a)vb vsihь Pm ot oktabь vsêhь êko Vin ot okt(a)vb vs(ê)hь o(ra)c(iê) v(i)še Oxf ot oktavb - êko v(i)̌se $\cdot$ Drag ot okt(a)vb $\cdot$ kakoe više Vat ${ }_{10}$ ot oktabs êk(o)že i više Brit
}

${ }^{28} \mathrm{n}$ (a) s(ve)t(a)go tomasa · službi iĉi ot m(u)č(eni)kь b(i)sk(upь) ] om. $\mathrm{N}_{2}$ Vat ${ }_{5}$ Mosk Pm Bar Broz Vat ${ }_{19}$ Oxf na d(a)nь s(ve)t(a)go tombsa služ bi iĉi ot m(u)č(e)n(i)kb b(i)sk(u)p(b) Ber ${ }_{2}$ na sv(e)t(a)go tomasa d(a)n' službi vse iĉi ot m(u)č(eni)ka b(i)sk(u)p VO n' s(veta)go tom(a)sa vse iĉi ot m(u)č(e)n(i)kb b(i)sk(u)pь - Mav na sv(eta)go tomasa službi - ili ot mučen(ika) bis(kups) - Rom v d(a)nь s(ve)t(a)go tomasa vsa ča manka iĉi ot ednoga b(i)sk(u)pa · $\check{c}($ tenie $) \cdot \mathrm{N}_{1}$ na s(veta)go tom(a)sa b(i)sk(u)pa i m(u)č(eni)ka sl(u)žbi iĉi v opĉ(i)ne a (=1)

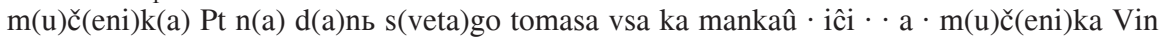
na s(veta)go tomasa mučenika $\cdot$ čte(nie) $\cdot a \cdot(=1)$ Drag n' s(veta)go tom(a)sa službi iĉi ot m(u)č(e)n(i)kb b(i)sk(u)pь Met na s(ve)t(a)go tom(a)sa m(u)č(eni)ka čt(enie) Vat ${ }_{10}$ na d(a)n' $\mathrm{s}(\mathrm{ve}) \mathrm{t}(\mathrm{a}) \mathrm{go}$ tom(a)sa službi iĉi ot $\mathrm{m}(\mathrm{u}) \check{c}(\mathrm{e}) \mathrm{n}(\mathrm{i})$ ka biskupa Brit

29 tomasa ] om. $\mathrm{N}_{1}$

${ }^{30}$ bratie m(i)lêiša rožd(a)stvo čtuĉe ] bratiê vzlûblena rožd'stvo čtuĉe br(a)tê m(i)lêiša $\mathrm{N}_{2}$ br(a)t(i)ê m(i)lêiša rožds'tvo čtuce $\operatorname{Vat}_{5}$ br(a)t(i)ê m(i)lêiša rois'tvo čtuce Mosk br(a)t(i)e milê(i)ša rožastvo čtuĉe Ber $_{2}$ br(a)t(i)e m(i)lêiša roistvo čtuûce $\operatorname{Pm}$ br(a)tie milêiša rožd'stvo čtuĉe VO br(ati)ê m(i)lêiša roistvo čtuce Bar br(a)tie m(i)lêiša roistvo čtuĉe Mav Met br(a)t(i)e m(i)lêiša roždabstvo čtuĉe $\cdot$ Rom br(a)tiê milêiša tomasa roistvo čtuĉe $\mathrm{N}_{1}$ br(ati)ê $\mathrm{m}(\mathrm{i}) l s i s ̌ a ~(!)$ roistvo čtuce Broz br(a)t(i)ê m(i)lêiša roistvo čtuĉe Vin br(a)t(i)ê m(i)lêiša roi-

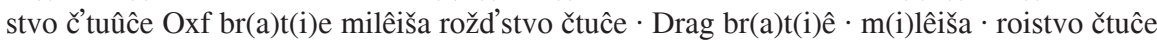
Vat ${ }_{10}$ br(a)t(i)ê m(i)lêiša roistvo čtuĉe Brit

${ }^{31}$ vsego ] v Vat ${ }_{5}$

${ }^{32}$ prêbivaniê ] prebivanie $\mathrm{N}_{2}$ Mosk prebivanii Vat ${ }_{5}$ prebivaniê Ber $_{2} \mathrm{Pm}$ VO Vat $_{19}$ Drag Brit prebiv(a)niê Bar Mav Broz Met i prebivaniê $\mathrm{N}_{1}$ prêbivanie Vat ${ }_{10}$

${ }^{33}$ znameniêh' ] znamin'êhь Mosk zlam(e)niêhь Drag

34 čisti ] i čudêsêhь Vat ${ }_{5}$ čis'toti Vat ${ }_{10}$ 


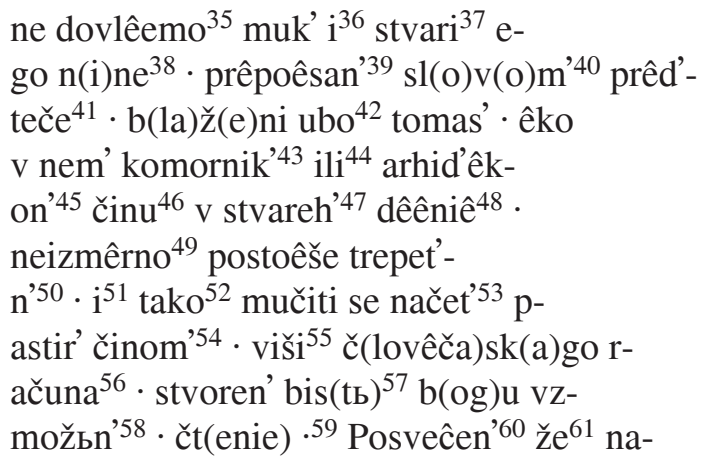

$\overline{35 \text { dovlêemo ] dovlêem' } \cdot \mathrm{N}_{1} \text { dovleemo Vat }}{ }_{10}$

36 i ] om. Pm

${ }^{37}$ stvari ] stvori Vat ${ }_{5}$ Rom

${ }^{38} \mathrm{n}(\mathrm{i})$ ne ] ispovêdati $\mathrm{Ber}_{2}$ is'pov(e)dati Brit n(i)ne ubo Pm

39 prêpoêsan' ] prepoêsanı $\mathrm{N}_{2}$ Vat $_{5}$ Mosk Ber $_{2}$ Bar Mav $\mathrm{N}_{1}$ Broz Pt Vat ${ }_{19}$ Drag prepoêsan' Met Brit

$\left.{ }^{40} \mathrm{sl}(\mathrm{o}) \mathrm{v}(\mathrm{o}) \mathrm{m}^{\prime}\right] \mathrm{sl}(\mathrm{o}) \mathrm{v}(\mathrm{e}) \mathrm{sem}$. Rom

${ }^{41}$ prêd'teče ] pred'teče $\mathrm{N}_{2}$ Ber $_{2} \mathrm{~N}_{1}$ Vat ${ }_{19}$ Brit preteče Vat ${ }_{5}$ pred'tečs Mosk Drag predsteče VO pred-

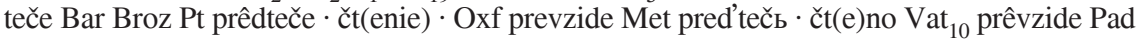

42 ubo ] om. $\mathrm{N}_{1}$

${ }^{43} \mathrm{v}$ nem' komornik' ] komornikb $\mathrm{v}$ nemb Vin

44 ili ] i $\mathrm{N}_{2}$ Mosk $\mathrm{N}_{1}$ Pt Vat ${ }_{10}$ om. Vat ${ }_{5}$

45 arhid'êkon' ] êrhidsêkonь Drag

46 činu ] om. Mav v' činu $\mathrm{N}_{1}$ Oxf Vat $_{10}$

${ }^{47}$ stvareh' ] stvarêhь Bar Broz Oxf stv'rêhь Mav stvarêh' Met

48 dêêniê ] diêniê Bar Broz deêniê Mav Pt

${ }^{49}$ neizmêrno ] neizmerno Vat ${ }_{5}$ Met nêiz'mêr'no Mosk neizmer'no Ber $_{2}$ Vat $_{10}$

${ }^{50}$ postoêše trepet'n' ] pos'toêše ne trepetanь $\mathrm{N}_{2}$ postoêše trepetanь Mosk Ber ${ }_{2}$ Bar Rom $\mathrm{N}_{1}$ Broz Drag Vin Vat ${ }_{10}$ postoêše trepetan' Pm Brit postoêšê trepetan Pt pos'toêše ne trepetanı čt(en)i(e) Vat ${ }_{19}$ pos' toêše trepetanь Oxf postoêše trep(e)tanь Met

51 i ] om $\mathrm{N}_{1}$

52 tako ] tbko Vat ${ }_{19}$

${ }^{53}$ mučiti se načet' ] n'čet' mučit' se Met

54 činom' ] dobri činomb $\mathrm{N}_{1}$

55 viši ] više $\mathrm{N}_{2}$ Mosk Ber 2 VO Bar Pm Rom $\mathrm{N}_{1}$ Broz Pt Vat $_{19}$ Vin Drag Oxf Vat ${ }_{10}$ Brit Vat $_{5}$ Mav

${ }^{56}$ računa ] om. Drag

57 bis(tb) ] estь Vat

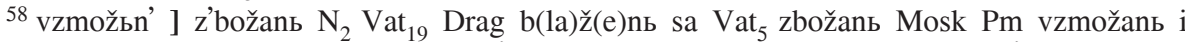
ugod(a)nь Ber ${ }_{2}$ vzbožanь Bar Broz s’bož(a)n $N_{1}$ vzmožan Pt vzmožanь Vin z’b(o)žanь Oxf

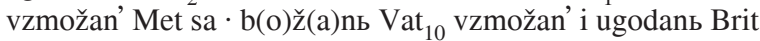

$59 \cdot$ čt(enie) · ] om. Ber ${ }_{2}$ Pm VO Bar Rom N Broz Pt Vat $_{19}$ Vin Oxf Brit · čtenie $\cdot$ b $\cdot(=2)$ Drag

${ }^{60}$ posveĉen'] pos'vêcen' $\mathrm{N}_{2}$ posvêcen' Ber ${ }_{2}$ posvêcen $\mathrm{Pt}$

61 že ] om. $\mathrm{N}_{1}$ 


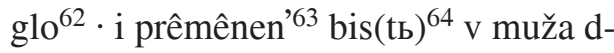
rugago $^{65} \cdot \mathrm{i}^{66}$ ciciliem $^{67}$ otai oblêče $\mathrm{e}^{68} \mathrm{se}^{69}$ do dimai $^{70} .71$ oĉe $\mathrm{e}^{72}$ običaem' ${ }^{73}$ daže $\mathrm{e}^{74}$ do plesnu ${ }^{75}$ nogu ot ciliciê $\cdot \mathrm{i}^{76}$ pod $^{77}$ rizami $^{78}$ gospod'skimi ${ }^{79}$ smêrenim' ${ }^{\text {'0 }}$ abitom' otainim' ${ }^{81}$ koludr'skim' . têlo s'vsêma ${ }^{82}$ udruči ra-

\footnotetext{
$\overline{62 \text { naglo ] n'glo Met }}$
}

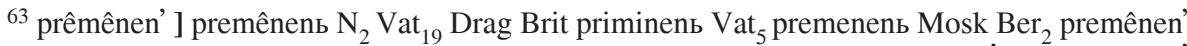
Pm prêmenenь Bar Mav Rom Broz prêmenen · Pt primenenь Oxf preminen’ Met primenen' Vat $_{10}$

${ }^{64}$ bis(tb) ] bis(tb) b(og)u Pm om. VO bi Vat ${ }_{10}$

65 drugago ] dr(u)goga Mosk

66 i ] om. Met

${ }^{67}$ ciciliem' ] ciliciems $\mathrm{N}_{2}$ Vat $_{5}$ Mosk Ber 2 Bar Mav Rom $\mathrm{N}_{1}$ Broz Vat ${ }_{19}$ Oxf Drag Brit ciliciem' $\mathrm{Pm}$ VO Vat ${ }_{10}$ ciliciem Pt

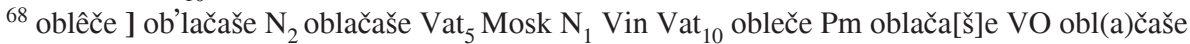
Bar Mav Broz oblêcê̂ Pt oblačaš(e) Oxf

${ }^{69}$ se ] sê Pt

70 dimai ] dim'i Vat ${ }_{5}$ Mav

${ }^{71}$ otai oblêče se do dimai $\cdot$ ] oblačaše se otai do dimai Vat ${ }_{19}$

72 oĉe ] oĉe že $\mathrm{N}_{2}$ i oĉe Vat $_{5}$ Ber $_{2}$ Vat $_{10}$ Brit

73 se do dimai · oĉe običaem' ] običaemb $\mathrm{N}_{1}$

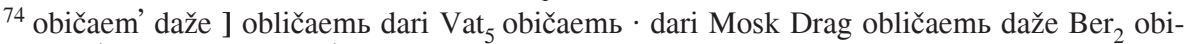
čaem' dari Pm obličaem' d[a]že VO običaemb dari Bar Broz Oxf Vat ${ }_{10}$ obič(a)emb dari Mav obličaemb dažde (!) Brit

75 plesnu ] plesan' Pm plêsnu Bar Mav Rom Broz Vin plêsanь Oxf

${ }^{76}$ ot ciliciê $\cdot$ ] om. $\mathrm{N}_{1}$ od ciliciê Pt ots ciciliê Vin ot ciliciê čt(enie) Oxf ot ciciliê Met

77 i pod ] pod Vat ${ }_{5} \mathrm{~N}_{1}$ pod' Mosk Rom

78 rizami ] riz'mi Met

${ }^{79}$ gospod'skimi ] om. Pm

${ }^{80}$ smêrenim' ] smêreni s'mêrenimb Ber $_{2}$ smerenimb Rom Vat $_{10}$ s'mêrenê $\mathrm{N}_{1}$ smerenim' Met smêreni smêreniemb Brit

${ }^{81}$ otainim' ] otai Pm om. $\mathrm{N}_{1}$ Vat $_{19}$

${ }^{82}$ koludr'skim' · têlo s'vsêma ] koludar's'kimь telo sav'sima $\mathrm{N}_{2}$ koludrskimь · toli (!) sьvsêma Vat $_{5}$ koludar's'kimь telo sav'sema Mosk koludarsskimь têlo svoe savs(ê)ma Ber ${ }_{2}$ kolud'r'skim' - têlo savsima Pm koludarsskim' t(ê)lo savs(ê)ma Bar kolud(a)rskims s(a)vs(ê)ma têlo Mav koludar'skims têlo savsêma Rom koludarskimb telo savsêma $N_{1}$ koludarskim' $t(\hat{e}) l o$ savs(ê)ma

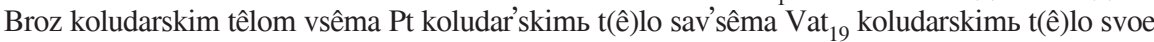
s'vsêma Vin koludarskims t(ê)lo savs(ê)ma Oxf koludar'skimь · t(ê)lo sbvsêma Drag koludar'skim'

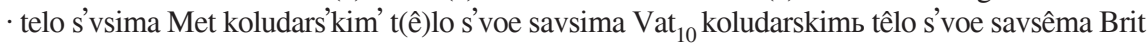




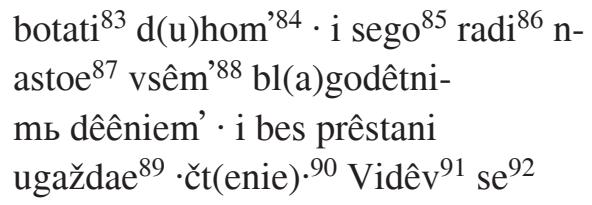

$$
\begin{aligned}
& \text { dêlatel'93 } \text { postavlen' }^{\text {94 }} \text { na }^{95} \\
& \text { nivê } \hat{e}^{96} \mathrm{~g}\left(\text { ospod)ni }{ }^{97} \cdot \mathrm{vb}^{98} \text { vinogradê }^{99}\right. \\
& \text { stražb · pьstir' v' ogradê } 100
\end{aligned}
$$

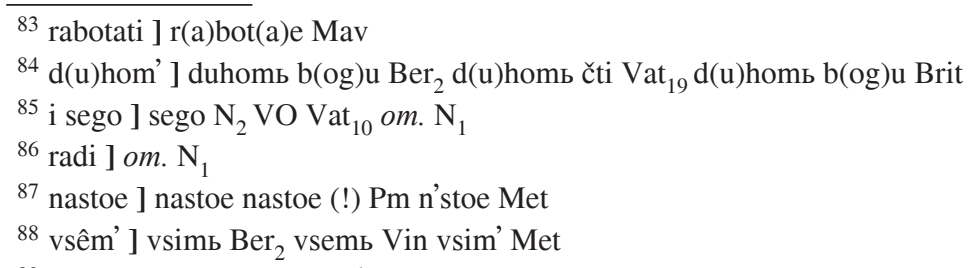

${ }^{89}$ bl(a)godêtnimь dêêniem' i bes prêstani ugaždae ] bl(a)godêtemь dêêniê prez' pres'taniê ugaž'dae $\mathrm{N}_{2}$ bl(a)g(o)d(ê)t(ni)m' dêêniê bez' prestaniê ugaždae Vat ${ }_{5}$ bl(a)godêt'nimb dêênê bez' pres'taniê ugaêše Mosk blagodet'nimb dêêniemb · i bêz' prestaniê ugaždae b(og)u va vsehь ti že g(ospod)i p(o)m(i)lui · Ber 2 bl(a)godêtem' · bêz' pristaniê ugaêe Pm bl(a)godêtnim' dêêniem' i bes prêstaniê ugaždae VO blagodêtemь diêniê bez prêstaniê ugaê Bar bl(a)god(ê)tnimь deêniem [i be]z' prest(a)ni ugaêe Mav blagodêtnimь dêênie · i bes' prêstaniê ugaždae Rom bl(a)g(o)dêtemь dêêniê bez' prestan'nê ugaždae $\cdot \mathrm{N}_{1}$ blagodêtemb diêniê bez prêstaniê ugaê Broz bl(a)g(o)detnim dêêniemb i b(e)s prêstani ugaždae ti že g(ospod)i p(o)m(i)lui n(a)sb b(og)u h(vali) Pt bl(a)g(o)d(ê)tem' dêêniê bez pres'taniê ugaždae $V a_{19}$ bl(a)godêtnimb dêêniems i bes prêstaniê ugaždae Vin bl(a)g(o)dêtemb dêêniê · i bes' prêstaniê ugajaetı Oxf blagodêtemь · dêêaniê besь prêstaniê ugaždae Drag bl(a)godêtnim' deêniem' i bes prestani ugaêe Met bl(a)g(o)dêtemь dêeniê bez' pristaniê ugaêe Vat ${ }_{10}$ blagodêtnimь · dêêniems · i bez prestaniê ugaždae b(og)u va v'sêhь Brit

$90 \cdot$ čt(enie) $\cdot]$ om. Pm Rm N 1 Vin Vat ${ }_{10}$ čteno v (=3) Pt $\cdot$ čtenie $\cdot$ čti treto $\cdot$ Drag

91 vidêv ] viêše $\mathrm{N}_{2}$ vidêv' že Ber ${ }_{2}$ vidit Pt vidêše Pad vidêv že Brit

92 se ] vse Vat ${ }_{10}$

93 dêlatel' ] delatelь $\mathrm{N}_{2} \mathrm{Vat}_{19}$ delatel Pt dêlateli Vat ${ }_{10}$

94 dêlatel' postavlen' ] postav'lenь delat(e)lь Ber ${ }_{2}$ postavlen' dêlatelь Brit

95 na ] n' Met

96 nivê ] nivi $\mathrm{N}_{2}$ Mosk Pm Bar Mav Broz $\mathrm{N}_{1}$ Drag Met Vat ${ }_{10}$

$97 \mathrm{~g}($ ospod)ni ] om. Mav

98 vь ] va Vat ${ }_{5}$ Mosk Pt Vat $_{10}$ i va Ber $_{2}$ Brit i v' Pm

99 vinogradê ] vinogradi Mosk $\mathrm{Vat}_{10}$ vinograde $\mathrm{Ber}_{2}$

100 psstir' v' ogradê ] pas'tirı va osêcê $\mathrm{N}_{2}$ pastirı v' osêcê Vat ${ }_{5}$ pas'tir' va osice Mosk pastirı vь ograde Ber $_{2}$ pastir' vb osici Pm past(i)rı va osicê Bar Broz v' ogr(a)dê Mav pastir' v' ogradê Rom pastirı vь osêcê $\mathrm{N}_{1}$ pastir va ograd Pt om. Vat ${ }_{19}$ pastirı vь ogradê Vin pas'tirı vь osicê Oxf pastirı va osêci Drag pastirı v' osicê Vat10 pıstir' va ogra[dê] Pad pastir' va ogradê Brit 


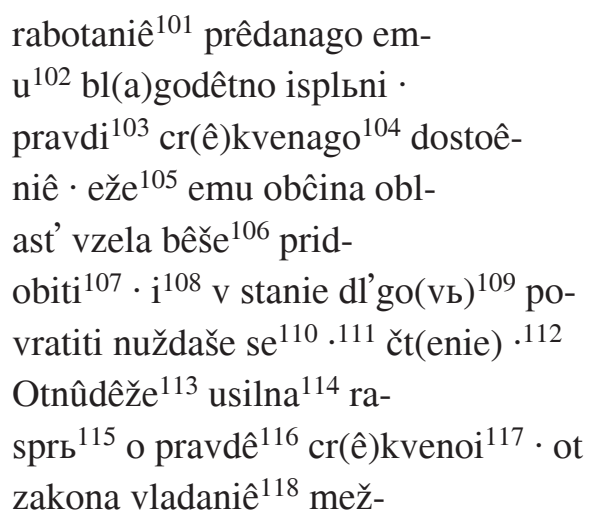

$\overline{101}$ rabotaniê ] om. Ber $_{2}$ Brit

102 prêdanago emu ] predanago emu $\mathrm{N}_{2} \mathrm{Vat}_{19}$ prêdnago emu Vat ${ }_{5}$ predanago emu predan(a)go emu Mosk predan(a)go emu Ber ${ }_{2}$ Brit pred(a)nago emu Bar Broz pridaniê emu $\mathrm{N}_{1}$ prêdanago jemu Pt pridanago emu Drg

${ }^{103}$ pravdi ] pr(a)vda $\mathrm{N}_{2} \operatorname{Vat}_{10} \operatorname{pr}(\mathrm{a}) \mathrm{vdnê} \mathrm{Vat}_{5} \mathrm{t}(\mathrm{i})$ ž(e) pravdi Pm pr(a)vdê Bar Broz Oxf pravdê $\mathrm{N}_{1}$ Pt Vin pravde Drag

104 cr(ê)kvenago ] crek'venago Mosk cr(ê)kv(e)nogo Broz crikvênago Pt

105 eže ] iže $\mathrm{N}_{1}$

106 obĉina oblast' vzela bêše ] op'ĉina v'zela b(ê)še oblas'tb $N_{2}$ opĉin'na vlastb vzela bêše Vat ob'ĉinia ob'las'tь v'zela beše Mosk ob'ĉina obl(a)stb v'zela biše Ber ${ }_{2}$ opĉin'na oblast' vzela b(ê)še Pm op'ĉina oblast' vzela bêše VO Pad opĉinna oblastı vzela b(ê)še Bar Broz opĉina oblastb vzela b(ê)še Mav op'cina oblastb vzela bêše Rom op'cina v'zela bê ob'lastь $\mathrm{N}_{1}$ opĉina oblastь vzela bêše Pt op'cina v'zela bêše $\cdot$ oblas'tь Vat $_{19}$ op'cina vzela bêše oblastı Vin op'cina ob'lastı v'zela b(ê)še Oxf op'ĉina oblastb vzela bêše Drag opĉina oblast' vzela b(ê)še Met op'ĉina oblast' v'zela b(ê) še Vat ${ }_{10}$

${ }^{107}$ pridobiti ] pridobit' $\mathrm{Pm}$

108 i ] om. $\mathrm{N}_{1}$

109 dl'go(vb) ] v dlgo(vb) Pm

110 nuždaše se ] nuêše se $\mathrm{N}_{2}$ Mosk Bar Mav Broz Drag Vat ${ }_{10}$ nuždaše Vat ${ }_{5}$ Rom nulaše se Oxf

111 povratiti nuždaše se ] nuêše se povrat(i)ti Met

112 c čt(enie) $\cdot]$ om. Pm Rom Vin Met Vat ${ }_{10}$ Brit čteno čti g (=4) Pt $\cdot g \cdot(=4)$ Rom čti $\cdot g \cdot(=4)$ Drag

113 otnûdêže ] otnudêže Vat ${ }_{5}$ Mosk Mav Pt Vin Oxf Drag ot'nudeže Ber ${ }_{2}$ ot'nudêže Rom otnudže Brit

114 usilna ] silna Oxf

115 rasprb ] ras'pra $\mathrm{N}_{2}$ Mosk Vat $_{19}$ Vat $_{10}$ raspra Vat $_{5}$ Pm Bar $\mathrm{N}_{1}$ Broz Oxf Drag rasparb Ber ${ }_{2}$ Rom Pt Vin rasp(a)rb Met raspar' Brit

116 pravdê ] pr(a)vdi Mav prav'd'vê (!) Brit

117 cr(ê)kvenoi ] crekvenêi Mosk crikvenoi Pt cr(ê)kvênoi Vat ${ }_{10}$

118 vladaniê ] vladan'ê Mosk Pm Bar vlad(an)ibê (!) Ber ${ }_{2}$ v'ladan'ê Brit 
dûn ${ }^{119}$ im' · i c(êsa)rem' ${ }^{120}$ ot an'glie v'z-

dviže $\mathrm{e}^{121} \mathrm{se} \cdot \mathrm{i}$ stvorše ${ }^{122}$ vê-

$\hat{c}^{123}$ vsed $^{12 n n e^{124}} \cdot$ pravdi onoe $^{125}$.

êko t๖žde c(êsa)rı i arhib(i)sku-

pi s ${ }^{126}$ družinoû ${ }^{127}$ svoeû pi-

smom'128 utvrbditi tvr'do s-

teza $^{129} \cdot$ ne zataûe ${ }^{130}$ krêp'-

ko ${ }^{131}$ i očito v nih' g(lago)laše $\mathrm{e}^{132} \cdot \mathrm{s}-$

vobod'stva $^{133} \operatorname{cr}(\hat{\mathrm{e}}) \mathrm{kvenago}^{134} \mathrm{pr}^{-}$

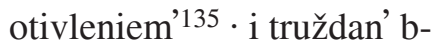

$\overline{119 \text { meždû ] meû } \mathrm{N}_{2}}$ Vat $_{5}$ Mosk Pm Bar Mav Rom $\mathrm{N}_{1}$ Broz Pt Vat ${ }_{19}$ Vin Oxf Met Vat ${ }_{10}$ meždu Ber $_{2}$ Brit

120 c(êsa)rem' ] k'ralemь $\mathrm{N}_{2}$ kralemb Vat $_{19}$

121 v'zdviže ] dviž’ Mav

122 stvorše ] s'tvoriše $\mathrm{N}_{2}$ Vat $_{19}$ stvoriše Vat ${ }_{5}$ Pm Bar Rom $\mathrm{N}_{1}$ Broz Pt Vin Vat ${ }_{10}$ s't'voriše Mosk s'tv(o)riše Oxf stvor(i)še Met

123 vêce ] viĉe Mosk Pm Bar Mav Broz Pt Oxf Met Vat ${ }_{10}$ veĉe $\mathrm{N}_{1}$ vêje Pad VO

${ }^{124}$ vsedınne ] v'sedan'ne $\mathrm{N}_{2}$ Mosk Broz Vin Oxf Vat ${ }_{10}$ vsed(a)nne Vat ${ }_{5}$ Pad vsedanıne Ber $_{2}$ v'sed(a)n'nee Vat ${ }_{19}$

125 pravdi onoe ] pr(a)vdê onoi Vat ${ }_{5} \operatorname{pr}($ a)vdi one Mosk pravde one $\mathrm{Pm} \operatorname{pr}(\mathrm{a}) \mathrm{vdê}$ one Bar Broz $\operatorname{pr}(a) v d i$ oni $\mathrm{N}_{1}$ prav'dê onoe Pt $\operatorname{pr}(\mathrm{a}) \mathrm{vde}$ one Oxf pravdi one Drag pr(a)vdi one $\cdot$ čt(enie) êko Vat $_{10}$

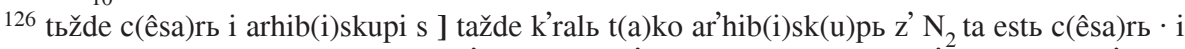
arhibiskupi s Vat ${ }_{5}$ tae c(êsa)rb i ar'hibisk(u)pi s' Mosk tažde c(êsa)rı ar'hiepisk(u)pi s' Ber ${ }_{2}$ tae c(êsa)rı t(a)ko i arhib(i)sk(u)pi s Pm tьžde c(êsa)r' arhibiskupi s VO tae c(êsa)rı · t(a)ko i arhib(i)sk(u)pь z Bar Broz tae c(êsa)rı i arhib(i)sk(u)pi z Mav tažde c(êsa)rı $\cdot$ i ar’hibiskupi s Rom taje c(êsa)rı · i arhib(is)k(u)pi sz (!) $\mathrm{N}_{1}$ taždê c(ê)s(a)rı i arhib(i)skups s Pt tažde kralı êko ar'hib(i)sk(u)pi z Vat ${ }_{19}$ tažde c(êsa)rb i ar'hib(i)sk(u)pi s' Vin taje c(ê)s(a)rı t(a)ko arhib(i)skupi s' Oxf taždê c(êsa)rı tako ar'hibiskupi s Drag tae c(êsa)rı i arhibiskupi z Met tae c(êsa)rb $\cdot$ i ar'hibiskup' z Vat ${ }_{10}$ tbžde c(êsa)rb $\cdot$ i ar'hibiskupi z Pad tažde c(êsa)rb arhiepiskupi s' Brit

127 družinoû ] družineû Broz

128 pismom' ] pismo VO Mav

129 steza ] stêza Ber ${ }_{2}$ sveza čti Vat ${ }_{19}$ finis Oxf

130 zataûe ] zavaûe (!) Vat ${ }_{5}$ zataûe i Mosk

131 krêp'ko ] krep'ko Mosk Ber 2 kripko Met

132 g(lago)laše ] gov(o)r(i)še Broz

133 svobod'stva ] svobododsstva (!) Pm slobod'stva Mav svobod'stviê Vat ${ }_{19}$

$134 \operatorname{cr}(\hat{\mathrm{e}})$ kvenago ] $\operatorname{cr}(\hat{\mathrm{e}}) \mathrm{kvênaga}(!) \mathrm{N}_{2} \operatorname{cr}(\hat{\mathrm{e}}) \mathrm{kv}(\mathrm{e})$ nago $\operatorname{Vat}_{5} \operatorname{cr}(\hat{\mathrm{e}})$ kvenogo Mosk $\operatorname{cr}(\hat{\mathrm{e}})$ kvênoga Ber $_{2}$ crikvenoga Pt cr(ê)kv(e)noga Met crêkvenoga Brit

135 protivleniem' ] protivleniem' · t(i) ž(e) Pm protivl(e)niem' · čt(en)i(e) Mav 
isi strast'mi ${ }^{136}$ velikimi ${ }^{137 .}$

i škodami ${ }^{138}$ prêteškimi $^{139}$ po-

gneten ${ }^{140} \cdot \mathrm{i}^{141}$ bes $^{142}$ čisla ras-

tegnen ${ }^{\prime 143} \mathrm{v}^{144}$ nečtovani ${ }^{145} \cdot$ čt(enie) ${ }^{146}$

$\mathrm{I}^{147}$ potom' iskahu ${ }^{148} \mathrm{i}^{149}$ semr'-

tiû ${ }^{150} \cdot$ êko stvar' cr(ê)kv-

ena ${ }^{151}$ ne oĉe $e^{152}$ plıno bêše

znana $^{153} \cdot$ i v têlê učiti ${ }^{154}(!)$ pr-

ogonahu ${ }^{155} \mathrm{i}^{156} \mathrm{~b}(\mathrm{la}) \mathrm{ž}(\mathrm{e})$ ni že tomas' .

izvoli ustanoviti $\cdot \mathrm{u}-$

$\overline{136}$ i truždan' bisi strast'mi ] · i tr(u)danı bistı strast'i $\mathrm{N}_{2}$ i trujenь bis(to) strastmi Vat ${ }_{5}$ truênь bis(tb) s'tras't'mi Mosk tr(u)danь bistı strast'mi Ber ${ }_{2}$ i trujan' bis(tь) strast'mi Pm i truždan' bis(tb) strast'mi VO i utruenь b(i)stı strast'mi Bar Broz i truênь bis(tь) strast'mi Mav i trudan bis(tb) strastmi Rom trujen' bistь s'trast'mi $\mathrm{N}_{1}$ i truždanь bis(tь) strastmi Pt i truždenь bivь strast'mi Vat ${ }_{19}$ i tružden b bis(tb) strastmi Vin i truên' bis(tb) strastmi Met i trudanı bi strastmi Vat ${ }_{10}$ i truždn’ bisi strastmi Pad i trudan' bistı strastmi Brit

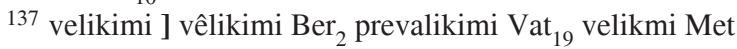

138 škodami ] šdodami (!) Drag

139 prêteškimi ] preteškimi $\mathrm{N}_{2}$ Mosk Vat $_{19}$ preteškimi Vat $_{5}$ Mav Pt Drag Met Brit pretêš kimi Ber $_{2}$ preteškimi Pm pret(e)škimi Bar Broz teškimi $\mathrm{N}_{1}$ Vin prevekšimi Vat ${ }_{10}$

140 pogneten' ] pognetênь Pt poginets (!) Vat ${ }_{10}$

141 i ] om. Vin

142 bes ] bez $\mathrm{N}_{2}$ Vat $_{5}$ Broz Vat $_{10}$ bez' Mosk Rom Vat ${ }_{19}$ Met Pad b(e)z' Bar

143 rastegnen' ] razbtegnenь $\mathrm{Ber}_{2}$ rastegne VO rastenenь Rom rastrgnenь Pt Drag

144 i bes čisla rastegnen' $\mathrm{v}] \mathrm{v} \mathrm{N}_{1}$

145 nečtovani ] nečtovanii $\mathrm{N}_{2}$ Rom $_{1} \mathrm{Vat}_{19}$ Vin Vat $_{10}$ nečtovanie Vat ${ }_{5}$ nečtovan’i vêlici Ber $_{2}$ nečtovan'i velicê Brit

146 - čt(enie) · ] om. Ber 2 Pm VO Bar Mav N Broz Vat $_{19}$ Vin Vat $_{10} \cdot d \cdot(=5)$ Rom Drag ti že $\mathrm{g}$ (ospod)i p(o)m(i)lui n(a)sb b(og)u h(vali) čt(e)no čti $\cdot \mathrm{d}(=5) \mathrm{Pt}$

147 i ] om. $\mathrm{N}_{1}$ Vin

148 iskahu ] iska Vat ${ }_{10}$

149 i ] ga Bar Mav Broz

150 semr'tiû ] semrtiû umoriti Vat ${ }_{5}$ Brit semr'tiû umoriti Ber ${ }_{2}$ sm'rtiû Vat $_{10}$

$151 \operatorname{cr}(\hat{\mathrm{e}})$ kvena ] $\operatorname{cr}(\hat{\mathrm{e}})$ kvêna Ber ${ }_{2} \operatorname{Vat}_{10} \operatorname{cr}(\hat{\mathrm{e}})$ kvênaê $\mathrm{N}_{1}$ crikvena Pt

152 ne oĉe ] om. $\mathrm{N}_{1}$ Vin

153 plıno bêše znana ] plno z'nana b(ê)še $\mathrm{N}_{2}$ plno b(ê)še znana Vat ${ }_{5}$ pl'no biše z'nana Mosk pl'no biše znana $\mathrm{Ber}_{2} b(\hat{e})$ še plno znana Pm plno biše zbnana Bar Broz plno ne b(ê)še oĉe z'nana $\mathrm{N}_{1}$ pl'no z'nana bêše Vat ${ }_{19}$ plno ne bêše oĉe z'nana Vin plna bêše znana Drag

154 têlê učiti ] telê očito $\mathrm{N}_{2}$ têlê očito $\mathrm{Vat}_{5}$ Mosk Pm Rom Vat ${ }_{19}$ Drag Met Vat ${ }_{10}$ VO Vin têle $\mathrm{Ber}_{2} \mathrm{t}(\hat{\mathrm{e}})$ lê očito Bar Broz telê oč〈ito) Mav telê očito $\mathrm{N}_{1}$ Pt têlê Brit

155 progonahu ] proganahu $\mathrm{VO}$

156 i ] i t t(i) ž(e) Pm ga $\cdot$ Mav om. $\mathrm{N}_{1}$ i $\cdot$ čti Vat ${ }_{19}$ 


\section{$43 \mathrm{a}$}

stupiti izvoli zlobêt $\hat{e}^{157}$

zaslan' ${ }^{158}$ ubo s neč stiû ·

$\mathrm{i}^{159}$ ot $^{160} \mathrm{~g}$ (ospodin)a papi ${ }^{161}$ tretago $^{162}$ alekьsan'-

dra $^{163} \mathrm{v}^{164}$ senon'165 č'stno priêt' bis(tь $)^{166}$.

i v manastir' ${ }^{167}$ pon'tiniêski ${ }^{168}$ n-

avlaĉ' no ${ }^{169}$ naporučen' ${ }^{170}$ bisi $^{171} \cdot$ čt(enie) $\cdot 172173$

157 b(la)ž(e)ni že tomas' · izvoli ustanoviti · ustupiti izvoli zlobê ] b(la)ž(e)ni že tomasь iz'voli us'tanovititi us'tupiti zlobi $\mathrm{N}_{2}$ b(la)ž(e)ni tomass voli ustanoviti ustupiti zlobi Vat b(la)ž(e)ni tomass iz’voli us'tanovititi i us'tupiti zlobi Mosk b(la)ž(e)ni že tom(a)sь izvoli ustanov(i)tit(i) se $\cdot$ ustupiti se zlobi ihь $\operatorname{Ber}_{2}$ b(la)ž(e)ni tomas' voli ustanoviti $\cdot$ i ustupiti zlobi Pm b(la)ž(e)ni že tomasь izvoli ustanoviti ustipiti (!) zlobê VO b(la)ž(e)ni že tomasь voli ustanovititi ustupiti zlobi Bar Broz b(la)ž(e)ni že t[omasь] izvoli ust(a)nov(i)ti · ustupiti zlobê $\cdot$ Mav b(la)ž(e)ni že tomass izvoli ustanovititi i ustupiti zlobê $\cdot$ Rom b(la)ž(e)ni tomasb volê ustanovititi i ustupiti zlobê $\mathrm{N}_{1} \mathrm{~b}(\mathrm{la}) \mathrm{z}(\mathrm{e})$ ni že tomas izvoli ostaviti i otstupiti zlobê · Pt b(la)ž(e)ni tomas' iz'voli stanoviti us'tupiti z'lobi · Vat ${ }_{19}$ b(la)ž(e)ni ubo tomasь volê ustanovititi i ustupiti z'lobê Vin b(la)ž(e)ni tomass volê ustanoviti ustupiti zlobê Drag b(la)ž(e)ni že tom(a)sь izvoli ustanoviti · ustup(i)ti izvoli zlobi Met b(la)ž(e)ni tomasь voli ustanovititi i ustupiti zlobê Vat ${ }_{10} \mathrm{~b}(\mathrm{la}) \bar{z}(\mathrm{e})$ ni že tomasь - izvoli us'tanovititi se i ustupiti se z'lobê ihь Brit

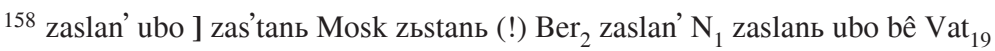

159 neč stiû · i ] nečas'tiû $\mathrm{N}_{2}$ Mosk nečastiû Vat ${ }_{5}$ Vin nečastiû i Ber ${ }_{2}$ Rom nečastiû · i Bar Broz neč(a)stiû i Mav nečastiû $\mathrm{N}_{1} \mathrm{Pt}_{\mathrm{Vat}}{ }_{10}$ neč(a)stiû i Met nečasstiû Brit nečsstiû Pm

160 ot ] o Met

161 papi ] pape $\mathrm{N}_{2} \mathrm{Vat}_{5}$ Pm Vin Drag Vat ${ }_{10} \mathrm{p}(\mathrm{a})$ pe Mosk Rom

162 tretago ] tretoga Vat ${ }_{5}$ Mosk Rom

163 alekssan'dra ] alêk'sandra Mav alêksan'dra Rom alêks(a)ndra Vat ${ }_{19}$

164 tretago alekbsan'dra v ] aleksandra tretago v Vin

165 senon ] seno Brit

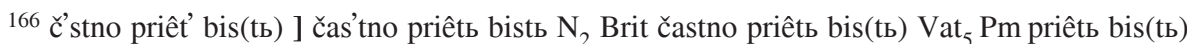
Mosk častno priêtb bistb Ber ${ }_{2}$ čast'no priêtb b(i)sto Bar Broz čast'no priêtb bis(tb) Rom častno priêt' bis(tb) $\mathrm{N}_{1}$ častno priêt b(i)st(b) Pt častno priêt bi Vat ${ }_{10}$

167 manastir' ] monostir' VO monostirb Mav Rom

168 pon'tiniêski ] ponteniênski Vat ${ }_{5}$ puntiên'ski Pm pon'tinen'ski $\mathrm{N}_{2}$ pon'tiniên's'ki Mosk pon'tiênski VO Mav Rom Drag pontiêns'ki Bar Broz pontiênski $\mathrm{N}_{1} \mathrm{Pt}$ Vin pon'tiniênski Vat ${ }_{19}$ pantiniênski Met pontiên'ski Vat ${ }_{10}$ pon'tiniên'ski Pad

169 navlaĉ'no ] navlaĉnê $\mathrm{N}_{1}$ navlas't'no Vat ${ }_{19}$

170 naporučen' ] napuručenь (!) Vat ${ }_{10}$

171 bisi ] bistb $\mathrm{N}_{2}$

172 čt(enie) · ] om. Vat ${ }_{5} \mathrm{~N}_{2}$ Mosk Bar Broz $\mathrm{N}_{1} \mathrm{t}(\mathrm{i})$ že g(ospod)i · čte(nie) Pm ·čte(nie) $\cdot \mathrm{e} \cdot(=6)$ Rom ti že g(ospod)i p(o)m(i)lui n(a)sb b(og)u hlvali (!) · čteno čti pra(vo) Pt ti že Vin čti Met

173 i v manastir' pon'tiniêski navlaĉ'no naporučen' bisi · čt(enie) · om. Brit Ber 


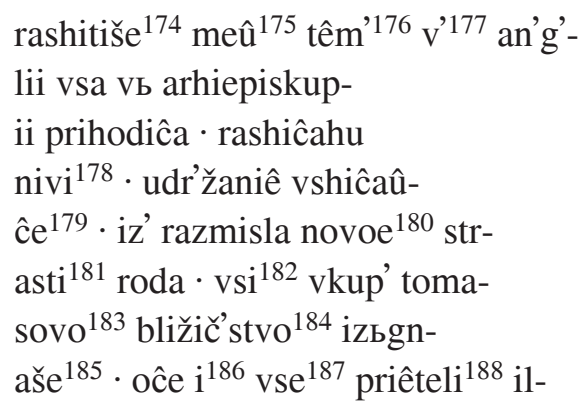

\footnotetext{
174 rashitiše ] rashitiše že Bar Broz

175 meû ] meždû $\mathrm{N}_{2}$ Vat $_{19}$ meždu Drag

176 têm' ] timь Mosk Bar Rom Broz Vat ${ }_{10}$ tim Pt tim' Pm

177 rashitiše meû têm' v' ] meû têmb rashitiše vsa v $\mathrm{N}_{1}$
}

178 v' an'g'lii vsa vb arhiepiskupii prihodiĉa · rashiçahu nivi ] va an'glii v'sa va ar'hibis'ku〈pi $\rangle$ i prihodiça razdrušahu nive $\mathrm{N}_{2}$ vsa v' anglii arhib(i)skupi prihodiĉa razdrušahu - nive $\mathrm{Vat}_{5}$ v in'glii (!) v'sa ar'hibiskupie prihodiça raz'd'rušahu nive Mosk va an'glii vsa suĉaê va ar'hiepiskupii prihodi rash(i)çahu - i nivi $\mathrm{Ber}_{2}$ vsa v' anglii v' arhib(i)skupii · prihodiĉa razdrušev(a)hu · nive Bar v' anglii vsa arh(i)b(i)sk(u)pi prihodiĉa · razdrušahu sela Pm v' an'glii vsa v' ar'hieb(i)sk(u)pii prihod(i)ĉa · r(a)shiĉ(a)hu nivi · Mav v' 〈a)n'glii · vsa v' ar'hibiskupii prihodiš ça $\cdot$ rashiĉahu nivi Rom vsa $\mathrm{v}$ anglie arhib(i)sk(u)pi prihodiĉa razdrušahu nivi i $\mathrm{N}_{1}$ vsa v' anglii v' arhib(i)sk(u)pii · prihodiça razdrušev(a)hu · nive Broz v anglii vsa v arhib(i)skupii prihodêĉa rashiĉahu Pt vь an'glii v'sa vь ar'hib(i)sk(u)pii prihodiĉa .

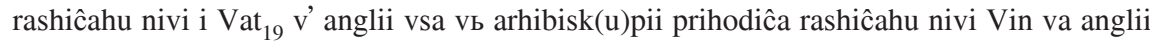
- vsa arhibiskupie prihodiça razdrušahu · nive Drag v' an'glii vsa v' arhieb(i)sk(u)pii (!) prihodiĉa · rashiçahu nivi Met v' an'glii v'sa arhi(e)piskupi · prihodiĉa raz'drušahu nive Vat ${ }_{10}$ v' anglii vsa va ar'hiepiskupii prihodiĉa · rashiĉahu nivi Pad va an'glii v'sa suĉaê v' arhiepiskupii prihodi rashiçahu $\cdot$ i nivi Brit

179 udr'žaniê vshiçaûce ] udržan'ê · rashiĉaûce Vat $_{5}$ ud'ržaniê v'sihiĉaûce Mosk udržaniê vshiĉaûcê Bar Broz udržanê rashiçaûce Pt

180 iz' razmisla novoe ] i razbmislanoe Ber $_{2}$ i r(a)zmisla novoe Mav iz' rasmis'la novoe Vat $_{19}$ i razmisla novoe Vin iz r'zmislnoe Drag iz rasmisla novoe Met i razmisl(a)noe Brit

181 strasti ] starosti Vat

182 vsi ] vse $\mathrm{N}_{2}$ Vat $_{5}$ Mosk Bar Pm N $_{1}$ Broz Vin Drag Vat $_{10}$ si Pt v'se Vat ${ }_{19}$

183 tomasovo ] tomasevo Brit

184 bližič’stvo ] bližič(a)stvo Vat $_{5}$ Ber $_{2}$ bližič(a)s't'vo Mosk bližičastvo Bar Broz Vin bližištvo Vat $_{10}$

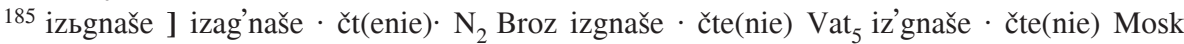
izag’naše $\cdot$ čte(nie) $\cdot$ Bar iz(a)gnaše ·čt(en)i(e)· Mav Vat ${ }_{19}$ iza(g)n(a)še $\mathrm{N}_{1}$ iz'gnaše $\cdot$ čt(en)i(e)

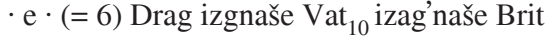

186 i ] om. $\mathrm{N}_{1}$

187 vse ] vsi Mav Rom Drag v'si Vat ${ }_{19}$ Vat $_{10}$

188 priêteli ] priêteli oĉo (!) Mosk 
$\mathrm{i}^{189}$ drugi ${ }^{190}$ iže koliždo ${ }^{191}$ emu pr-

istoêše ${ }^{192} \cdot$ bez $^{193}$ razbora $^{194} \mathrm{sv-}$

êdêniê ${ }^{195}$ ili $^{196}$ gnêva ${ }^{197}$ dosto-

êni ${ }^{198} \cdot$ ili reda ${ }^{199}$ vrêmene $^{200} \cdot$ ili

muž ski ${ }^{201} \cdot i^{202}$ žen'ski pol'203 vkup' i-

spueni biše $\mathrm{e}^{204} \cdot$ vistinu st-

ari i ${ }^{205}$ prêstari $^{206} \cdot$ i kvekaûca ${ }^{207}$

čeda ispueni biše $\mathrm{e}^{208} .209$ čt(enie) $\cdot 210$

Elikože im' vzrastom' 1-

êti $^{211}$ pristoêhu ${ }^{212} \cdot$ kosneniem'

$\mathrm{s}(\mathrm{ve}) \operatorname{tos}(\mathrm{ve})$ tihb $^{213}$ kleti se ${ }^{214}$ nužden-

189 ili ] i Pt

190 drugi ] druzi Rom drugi tomasovi · i Vat ${ }_{19}$

191 iže koliždo ] iže Vat ${ }_{5} \mathrm{~N}_{1}$ i ki koli Mav ki koližde Broz

192 emu pristoêše ] emu pris'toêhu $\mathrm{N}_{2}$ Vat $_{5}$ Mosk emu pristoêhu Ber ${ }_{2}$ VO Bar Pm Rom N $\mathrm{N}_{1}$ Broz Vin Drag Vat ${ }_{10}$ Brit nemu pristoêhu Mav pristoêhu emu Vat ${ }_{19}$

193 bez' ] prêz' Rom brez Pt Vat ${ }_{10}$

194 razbora ] rabora zbora (!) VO rabora (!) i Drag

195 svêdêniê ] svêdeniê $\mathrm{Ber}_{2} \mathrm{~N}_{1}$ Vat $_{10}$ Brit svedeniê Pt

196 ili ] i $\mathrm{N}_{1}$

197 gnêva ] gneva Pt gniva Vat ${ }_{10}$

198 dostoêni ] dos'toini $\mathrm{N}_{2}$ Vat $_{19}$ dostoêniê Ber 2 Bar Pm Broz dostoini VO N Pt Vin Vat $_{10}$

199 reda ] rêda Vat ${ }_{10}$

${ }^{200}$ vrêmene ] v'rêmenь $\mathrm{N}_{2}$ vreme(ne) Mosk vrem(e)nê Ber ${ }_{2}$ vrimene Bar Broz vrem(e)ne Pt om. Vat $_{19}$ vrêmenь Drag vrim(e)ne Met vrêmenê Brit

201 mužski ] mužaski Ber ${ }_{2}$ Rom $_{1}$ Vat $_{10}$ Brit muž ski polı Vat ${ }_{19}$ mužski polı Vin

202 i ] ili $\mathrm{N}_{2}$ Vat $_{5}$ VO Bar Pm Mav N ${ }_{1}$ Broz Vat $_{19}$ Drag Met Vat $_{10}$

203 pol' ] v'si Vat ${ }_{19}$ om. Vin

204 biše ] bêše Vat ${ }_{5}$ Vat $_{19}$

205 i ] om. $\mathrm{N}_{1}$

206 prêstari ] pres'tari $\mathrm{N}_{2}$ Ber $_{2}$ Brit prestari Mosk Bar Broz Vat ${ }_{19}$ prest(a)ri Mav Met om. $\mathrm{N}_{1}$

207 kvekaûĉa ] k'vêkaûĉa $\mathrm{N}_{2}$ k'vekaûce Mosk kvêkaûĉa Ber ${ }_{2}$ kvekaûce VO N ${ }_{1}$ Vat $_{10}$

208 ispueni biše ] ispuĵ(e)ni beše $N_{1}$ ispueni bêše Vin ispuĵeni biše Drag Pm

209 vistinu stari i prêstari · i kvekaûce čeda ispueni biše ] om. Vat ${ }_{5} \mathrm{Pt}$

$210 \cdot$ čt(enie) $\cdot]$ om. $N_{1}$ Vin Pad Brit čti Bar $\check{z} \cdot(=7)$ Rom čtenie čti $\cdot \check{z} \cdot(=7) \mathrm{Pt} \cdot$ čt(en)i(e) $\cdot \check{z}$ $\cdot(=7)$ Drag finis Pm Vat 10

211 lêti ] om. Vat ${ }_{19}$ leti Met

212 pristoêhu ] pristoêhu êk(o) stoêhu Vat ${ }_{5}$ pris'toêše Vat $_{19}$

${ }^{213}$ kosneniem' s(ve)tos(ve)tihь ] kos'nutiemb s(ve)tos(ve)tihь $\mathrm{N}_{2}$ Vat ${ }_{5}$ Mosk kasneniem' s(ve)tos(ve)tims VO kosnutiems s(ve)tos(ve)tih' Bar Broz kosnutiems s(ve)tos(ve)tihь $\mathrm{N}_{1}$ Vin Drag ${ }^{214}$ se ] sê Pt 


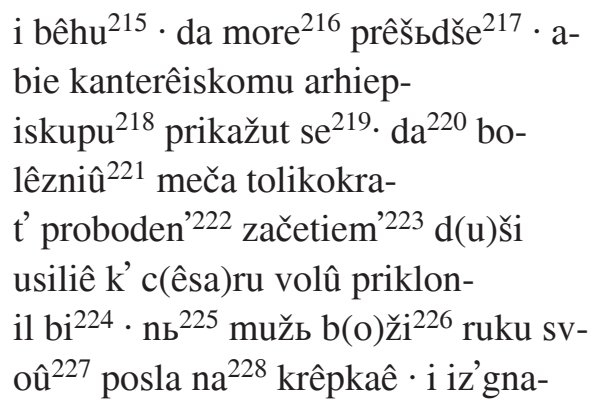

niem' škodi i sramoti i pon-

ošenie $^{229}$ ot roda $\cdot$ i priêtelı s-

$\overline{215}$ nuždeni bêhu ] nueni biše $\mathrm{N}_{2}$ Mosk nueni bêhu Vat ${ }_{5}$ Bar Broz nuždeni bihu Ber $_{2}$ nueni bihu Mav nuždeni buhu (!) Rom nujeni biše $\mathrm{N}_{1}$ nuždeni biše Vat $_{19}$ Vin nueni b(i)hu Met

216 more ] morê Pt

217 prêšbdše ] prišad'še $N_{2}$ prešadše Vat ${ }_{5}$ prešad'še Mosk $N_{1}$ Vat ${ }_{19}$ priš(a)dše Ber ${ }_{2}$ prešadšê Bar Broz prêd'š(a)d'še Mav prêšad'še Rom priš(a)d'še Drag preš(a)d'še Met prived(o)še i Brit

${ }^{218}$ kanterêiskomu arhiepiskupu ] kan'turêis'komu ar'hib(i)sku(pu) $\mathrm{N}_{2}$ kanturêiskomu arhibiskupu Vat ${ }_{5}$ kan'turêiskomu ar' hibiskupu Mosk kan'tierêiskomu ar' hiepiskupu Ber ${ }_{2}$ kanteriiskomu arhiepiskupu VO kanturineiskomu arhib(i)sk(u)pu Bar Broz kon'terêiskomu arhibisk(u)pu Mav kon'terêiskomu arhiepiskupu Rom kanturêiskomu arhib(i)sk(u)pu $\mathrm{N}_{1}$ kanterêiskomu arhib(i)skupu Pt kanturienskomu b(i)sk(u)pu Vat ${ }_{19}$ kantorêiskomu arhibiskupu Vin kan'turêiskomu arhibiskupu Drag kanterêskomu arhieb(i)sk(u)pu Met kьanter'êskomu arhiepiskupu Pad k'an'tierêiskomu arhiepiskupu Brit

219 prikažut se] prikažût' se VO prikažut se $\cdot$ da prikažut se Rom

220 da ] i da Drag

221 bolêzniû ] bolezniû Met

222 proboden' ] pribodenь Drag

223 začetiem' ] začetimb $\mathrm{N}_{2}$ začetomb Vat ${ }_{19}$

${ }^{224}$ k' c(êsa)ru volû priklonil bi ] k' kralû voleû prik'lonil' se bi $\mathrm{N}_{2} \mathrm{k}$ c(êsa)ru voleû priklonil se bi Vat ${ }_{5}$ Bar Broz k c(êsa)ru voleû prik'lonil' se bi Mosk k c(ê̂sa)ru volû uklopil bi Mav k c(êsa)ru voleû prik'lon' se bê $N_{1}$ k c(êsa)ru voleû priklonil bi Pt k c(êsa)ru voleû priklonil' se bi čti Vat ${ }_{19}$ k' c(êsa)ru volû priklonil se bê Vin k' c(êsa)ru voleû priklonil se bi Drag

${ }^{225}$ пь ] na $\mathrm{N}_{2}$ Vat $_{5}$ Ber $_{2}$ Bar Rom Broz N ${ }_{1}$ Pt Vat $_{19}$ Vin Drag Brit sa Mosk n(a) Met

226 b(o)ži ] božii Mosk

227 ruku svoû ] r(u)koû svoeû Mav

228 na ] n' Met

${ }^{229}$ i iz'gnaniem' škodi i sramoti i ponošenie ] i izag'naniemb škodê sramotu $\cdot$ i ponošeniê $\cdot N_{2}$ izgnaniemb škode i sramote i ponošeniê Vat ${ }_{5}$ izag'naniemb škode i s'ramoĉeniemb i ponošenie Mosk i iz'gnaniem' škodi i sramoti i ponošeniê VO i izag'naniemb škode i sramote i ponošenie Bar i iz'gn(a)niemь škodi i sr(a)moti · i ponoš(e)niê Mav izagnaniem’ škodi i 
puždeniêê 230 za h(rbsto)vo ime krêp'ko $^{231}$ trıpê $\hat{e}^{232} .233$ niedinoû ${ }^{234}$ skrušen'

ili izmênen'235 ${ }^{\prime 2}$ sramotoû ${ }^{236} \cdot$ čtt(enie) $)^{.237}$

Tolika ${ }^{238}$ ubo bê ${ }^{239}$ krêpost'

isp(o)vêdnika h(rbsto)va $a^{240} .241$ da d-

rugi $^{242}$ svoe učiti vidêl'243

se bi · êko vsakomu ${ }^{244}$ krêpkomu

z(e)mla dêdina ${ }^{245}$ est' ${ }^{246}$ sliša-

v že c(êsa)rı utvr'ždenie ${ }^{247}$ ego krê-

sramoti ponošeniê $N_{1}$ i izagnaniemь škode i sramote i ponošenie Broz i izagnaniem škodi i sramoti i ponošeniem Pt i izagnanie škodi i sramoti i ponošenie Vat ${ }_{19}$ iz'gnanie škode $\cdot$ i sramoĉe i ponošeniê Drag i izagn(a)niemь škodi i sramoti · i ponošenie Brit

230 ot roda · i priêtelı spuždeniê ] ot roda i priêtelı is' pueniê $\mathrm{N}_{2}$ Mosk ot roda i priêt(e)lı is'pueniê $\mathrm{Ber}_{2}$ ot roda i priêtelb ispuen'ê Vat ${ }_{5}$ om. VO ot roda i priêtelb spueniê Bar Broz reda i priêtelı spueniê Mav ot roda · priêt(e)lb spueniê Rom ot roda i priêtelı spujeniê $\mathrm{N}_{1}$ ot roda i priêtel spuždêniê Pt ot roda i priêtel' spueniê Vat ${ }_{19}$ ot roda i priêtelb s'pujeeniê Drag ot roda i priêtel' spueniê Met ot roda i priêt(e)l ispueniê Brit

231 ime krêp'ko ] іmеь k'rêpo (!) $\mathrm{N}_{2}$ ime krep'ko Mosk ime krepko Pt ime kripko Met

232 h(rısto)vo ime krêp'ko trıpê ] ime h(rbsto)vo krêp'ko trpê Vat ${ }_{19}$

233 trьpê $\cdot]$ trpê $\cdot$ i $\mathrm{N}_{1}$

234 niedinoû ] niednoû Drag

235 ili izmênen' ] om. Ber ${ }_{2}$ Brit ili izmenen' Rom ili izmenen Pt

${ }^{236}$ sramotoû ] vaĉinoû $\mathrm{N}_{2}$ Vat $_{5} \mathrm{~N}_{1}$ taĉinoû Mosk Drag s'ramotoû · ti že g(ospod)i p(o)m(i)lui $\mathrm{Ber}_{2}$ v'ĉinoû Bar Broz

237 . čt(enie) $]$ om. Ber ${ }_{2} V_{\text {at }}{ }_{19}$ Met · ti že g(ospod)i p(o)m(i)lui · čti Bar čti 3 (= 8) Pt ti že Vin čt(en)i(e) 3 (= 8) Drag

238 tolika ] toliko VO Rom

239 bê ] bis(tь) Vat 5 bi Mosk om. Rom Pt bi Met

240 krêpost' isp(o)vêdnika h(rbsto)va ] krepos'tı is'povednika h(rbsto)va Mosk ispov(ê)dn(i)ka $\operatorname{kr}(\hat{e})$ postb h(rısto)va $\cdot$ Rom kripost' ispov(ê)dn(i)ka h(rısto)va Met

241 bê krêpost' isp(o)vêdnika h(rısto)va · ] krêpos'ts bê isp(o)v(ê)dnika h(rbsto)va Vat ${ }_{19}$

242 drugi ] drurugi (!) Rom

243 vidêl' ] vidêl že Vat ${ }_{5}$ videl' Mosk Ber $_{2}$ Vat $_{19}$ videl Mav

244 vsakomu ] vsьkomu VO

${ }^{245}$ z(e)mla dêdina ] z(e)m(a)Ina didina Vat ${ }_{5}$ (e)mla didina Mosk Bar Broz Pt z(e)mla did(i)na

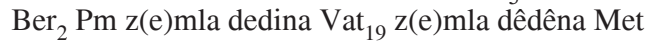

246 finis $\mathrm{Vat}_{19}$

247 c(êsa)rı utvr'ždenie ] k'ralı ut'vrenie $\mathrm{N}_{2}$ c(êsa)rı utvrenie Vat ${ }_{5}$ c(êsa)rı ut'vrenie Mosk c(êsa)rı utvr'enie Ber ${ }_{2}$ Met c(êsa)rb utvrjenie Bar $N_{1}$ Broz c(êsa)rı utv'renie vis(o)koe Mav c(êsa)rı utvrenie Brit 
posti $^{248} \cdot$ poslanimi ${ }^{249}$ listi

po eterêh' ${ }^{250}$ opatêh ${ }^{251}$ čisteri-

en'skago ${ }^{252}$ reda $\cdot$ na kapitul-

i vsego sbora ${ }^{253}$ listi $^{254}$ prêtb-

benimi ${ }^{255} \cdot$ ot pon'ciên'skago ${ }^{256}$ man-

astira smutiti ${ }^{257} \mathrm{ga}^{258}$ pečalova $^{259} \cdot$ čt(enie) $\cdot 260$

Boe $^{261}$ že se b(la)ž(e)ni tomas' pr-

irokom'262 svoim' mužem' s(ve)t-

im' semr'ti približani-

$\hat{\mathrm{e}}^{263} \cdot$ voleû svoeû otstupi .

nb $^{264}$ prêžde $^{265}$ neže izide ${ }^{266} \cdot$ b(o)ži-

mь ${ }^{267}$ êvleniem' ukrêplen' bisi .

\footnotetext{
248 ego krêposti ] ego krepos'ti Mosk krêposti ego Mav

249 poslanimi ] i poslanie $\mathrm{Ber}_{2}$ poslanie Brit

250 eterêh' ] eterihь $\mathrm{N}_{2}$ Bar Rom Broz Brit et(e)rihь Vat ${ }_{5}$ Mosk Ber ${ }_{2}$ četirêh' VO eterih Pt etêrêhь Vin et(er)ihь Met

251 opatêh' ] opatihь Mosk op(a)tihь Bar Broz opatehь Rom

252 čisterien'skago] čis'tirien'skago $\mathrm{N}_{2}$ česteriênskoga Vat ${ }_{5}$ česteriên'skago Moskčisteriên'sk(a)go $\mathrm{Ber}_{2}$ čistirien'skago Mav čisterieskago $\mathrm{N}_{1}$ Vin čistêriênskoga Pt česterienıskago Drag čisteriên'skago Brit

${ }^{253}$ kapituli vsego sbora ] kapituli v'sego zbora $\mathrm{N}_{2}$ Ber $_{2}$ kapituliê svoego zbora Vat ${ }_{5}$ kapitolu v'sego z'bora Mosk kapituli vsego zbora VO Pt Vin Pad kapit(u)li vsego zbora Bar Broz k(a)pituli vsego zbora Mav k(a)p(itu)li vsego z'bora $\mathrm{N}_{1}$ kapiteli vsego zbora Drag kap(i)tuli vsego zbora Met kapitulê vsego zbora Brit

254 listi ] om. Pt

255 prêtbbenimi ] prib'enimi $\mathrm{N}_{2}$ pritb(e)n(i)mi Mosk v'spreĉae Ber $_{2}$ pridbenimi Bar Broz prêt'bênimi Mav $\mathrm{N}_{1}$ pritbênimi Rom priêtbeni Pt pritbenimi Met vsprêĉae Brit

256 pon'ciên'skago ] ponciênskogo Vat ${ }_{5}$ ponciênskoga $\mathrm{Pt}$

257 smutiti ] spuditi Mav

258 ga ] om. $\mathrm{N}_{1}$ i Vin

259 pečalova ] pečblova zloboû Ber $_{2}$ pečalova ti že VO pečelova $\mathrm{N}_{1}$ finis Bar Mav Broz pečalova $a d d$. zloboû Brit

$260 \cdot$ čt(enie) $\cdot] \cdot \mathrm{z} \cdot(=9)$ Rom ti že g(ospod)i $\cdot$ čteno čte pra(vo) Pt om. Vin Pad čt(en)i(e) deveto $\cdot \mathrm{z} \cdot(=9)$ Drag

261 boe ] boi Mosk

262 prirokom' ] priroka Vat ${ }_{5}$ pror(o)komь Mosk pripror(o)komь (!) Ber $_{2}$ prirokov' Met Pad

263 približaniê ] približeniê $\mathrm{N}_{2}$ Vat $_{5} \mathrm{~N}_{1}$ Drag prib'liženiê Mosk

264 nь ] na $\mathrm{N}_{2}$ Vat $_{5}$ Mosk Ber, VO Rom $\mathrm{N}_{1}$ Pt Vin Drag Brit

265 prêžde ] prêde Vat ${ }_{5}$ prie Mosk prežde $\mathrm{Ber}_{2}$ prêle $\mathrm{N}_{1}$ illeg. Met

266 neže izide ] nežê izidê Pt

267 b(o)žimb ] b(la)ž(e)ni(mb) Pad
} 


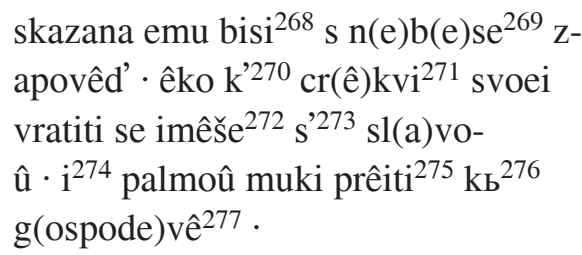

\section{LATINSKI TEKST}

Latinski je tekst preuzet iz BRAINERD SLOCUM 2004: 212-214 s grafijom prilagođenom klasičnomu latinskom.

In sancti Thomae episcopi et martyris omnia dicuntur de uno martyre lectiones vero de passione eius.

\section{Lectio I.}

Gloriosi martyris Thomae, fratres carissimi, natalem celebrantes, quia totius vitae et conversationis eius insignia recolere non sufficimus, passionis eius modum causamque succinctus sermo percurrat.

Beatus igitur Thomas sicut in cancellariae vel archidyaconatus officio in rebus gerendis incomparabiliter extiterat strenuus, ita et post susceptum pastoris officium supra humanam aestimationem factus est Deo devotus. Consecratus enim repente mutatus est in virum alium. Cilicium clam induit, femoralibus etiam usus est ad poplites cilicinis. Et sub vestis clericalis honestate habitum celans monachalem, carnem prorsus coegit servire spiritui, Deo studens om-

268 ukrêplen' bisi · skazana emu bisi ] ukrêpêlenь (!) bistı s'kazana bistı emu $\mathrm{N}_{2}$ ukrêplenь bis(tb) i skazana emu bis(tb) Vat ${ }_{5}$ ukreplenь bis(tb) $\cdot$ s'kazana emu bis(tb) Mosk ukreplenь bistb $\cdot$ i skazana emu bistь Ber, ukrêplen' bis(tь) $\cdot$ skazana emu bis(tь) VO ukrêplenь bis(tь) - skazana emu bist(ь) Rom Vin Drag ukrêplenь bis(tь) · i skazana emu bis(tь) $\mathrm{N}_{1}$ ukrêplenь bistb · skazana emu bist Pt ukrêplen' bis(tb) $\cdot$ skaz(a)na emu bis(tb) Met

$\left.{ }^{269} \mathrm{~s} \mathrm{n}(\mathrm{e}) \mathrm{b}(\mathrm{e}) \mathrm{se}\right] \mathrm{om}$. VO

${ }^{270}$ k' ] om. Rom

271 cr(ê)kvi ] crikvi $\mathrm{N}_{2}$ crikvê Pt cr(ê)kvê Met

272 imêše ] imêše i $N_{2}$ imeše Mosk imiše Met

273 s' ] sa Ber 2 Pt Brit

274 i ] i s' Mosk

275 prêiti ] preiti $\mathrm{N}_{2}$ Vat $_{5}$ Mosk $\mathrm{N}_{1}$ priêti Ber $_{2}$ VO Pt Drag Brit

276 kb ] ka Mosk Pt Brit

$277 \mathrm{~g}$ (ospode)vê ] g(ospod)u Vat ${ }_{5} \mathrm{~g}$ (ospode)vê $\cdot$ ti že $\mathrm{g}\left(\right.$ ospod)i Ber $_{2} \mathrm{~g}($ ospode)vê $\cdot$ ti že VO g(ospode)vê ti že g(ospod)i p(o)m(i)lui n(a)sь b(og)u h(vali) Pt 
nium virtutum exercitio sine intermissione placere. Sciensque se cultorem positum in agro Dominico in vinea custodem, pastorem in caulis, ministerium sibi creditum studiose complevit. Iura et dignitates ecclesiae, quas publica sibi potestas usurpaverat, resarcire et in statum debitum revocare conatus est. Unde gravi quaestione super iure ecclesiastico et regni consuetudinibus inter ipsum et regem Anglorum exorta, coadunto consilio propositae sunt consuetudines illae quas idem rex tam archiepiscopi quam suffraganeorum suorum scripto roborari pertinaciter exegit. Negavit constanter archiepiscopus, manifestam in eis asserens libertatis ecclesiasticae subversionem. Affectus est igitur contumeliis immensis, damnis gravioribus attritus, et innumeris lacessitus iniuriis. Tandem sibi morte intentata, quia causa ecclesiae nondum plene innotuerat, et personalis videbatur persecutio, cedendum censuit esse malitiae. Actus ergo in exilium a domino papa Alexandro Senonis honorifice susceptus est, et in monasterio Pontiniacensi studiose commendatus.

\section{Lectio II.}

Confiscantur interim in Anglia omnes archiepiscopi reditus, vastantur praedia, possessiones diripiuntur, et excogitato novo supplicii genere, tota simul proscribitur Thomae cognatio. Omnes etiam amici eius, vel familiares, vel quicumque eum quocumque titulo contingebant, sine delectu conditionis aut fortunae, dignitatis aut ordinis, aetatis aut sexus, pariter relegantur. Nam et senes et decrepiti, vagientes in cunis, et mulieres in puerperio decubantes, in exilium acti sunt. Quotquot autem discretionis annos attigerant, tactis sacrosanctis iurare compulsi sunt, quod mari transito statim Cantuariensi archiepiscopo se praesentarent, ut vel compassionis gladio totiens confossus, conceptum animi rigorem ad regis voluntatem inflecteret. Sed vir Dei manum suam mittens ad fortia, exilium, damna, contumelias, et opprobria, parentum et amicorum proscriptionem pro Christi nomine constanter sustinuit, nulla prorsus fractus aut immutatus iniuria. Tanta namque fuit confessoris Christi constantia, ut omnes coexules suos docere videretur, quid omne solum forti patria est.

\section{Lectio III.}

Audiens ergo rex immobilem eius constantiam, directis per abbates quosdam Cisterciensis ordinis ad capitulum generale litteris comminatoriis, eum a Pontiniaco perturbare curavit. Timens autem beatus Thomas occasione sui viris sanctis imminere dispendium, sponte recessit. Sed antequam inde progrederetur, divina revelatione confortatus est, ostenso sibi caelitus inditio quod ad ecclesiam suam rediturus esset cum gloria, et per palmam martyrii migraturum ad Dominum. 
A. MIHALJEVIĆ, Služba u čast sv. Tomi Becketu u hrvatskoglagoljskim ... SLOVO 70 (2020)

\section{KRATICE IZVORA}

BrBar = Baromićev tiskani brevijar, 1493. g., Venecija.

BrBer $_{2}=$ II. beramski brevijar, 15. st., Ljubljana, NUK, Ms 163.

BrBrit $=$ Britanski brevijar, 15. st., London, British Library, Ms. Add. 31.951 .

BrBroz = Brozićev tiskani brevijar, 1561. g., Venecija.

BrDrag = Dragućki brevijar, 1407. g., Zagreb, HAZU, III b 25.

BrMav = Brevijar popa Mavra, 1460. g., Zagreb, NSK, $R 7822$.

BrMet = Brevijar Metropolitanske knjižnice u Zagrebu, 1442. g., Zagreb, Metropolitanska knjižnica, $M R_{161}$.

BrMosk = Moskovski brevijar, 1442. - 1443. g., Moskva, Rossijskaja gosudarstvennaja biblioteka, Rumjancevskij muzej, F. 270, 51/1481.

$\mathrm{BrN}_{1}=$ I. novljanski brevijar, 1459. g., Novi Vinodolski, Župni ured.

$\mathrm{BrN}_{2}=$ II. novljanski brevijar, 1495. g., Novi Vinodolski, Župni ured.

BrOxf $=$ Oksfordski brevijar - misal, 14. st., Oxford, Bodleian Library, Ms. Canon. Lit . 172.

BrPad = Padovanski brevijar, sredina 14. st., Padova, Biblioteca Universitaria, MS 2282.

$\mathrm{BrPm}=$ Pašmanski brevijar, druga polovica 14. st., Zagreb, HAZU, III b 10.

$\mathrm{BrPt}=$ Prvotisak brevijara, 1491. g., Venecija, Biblioteca nazionale Marciana, Breviario glagolitico, Inc. 1235.

BrRom $=$ Rimski brevijar D 215, 15. st., Rim, Biblioteca Apostolica Vaticana, Cap. S. Pietro, D 215.

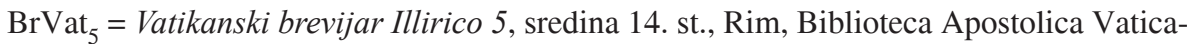
na, Borg. Illir. 5.

BrVat $_{10}=$ Vatikanski brevijar Illirico 10, 1485. g., Rim, Biblioteca Apostolica Vaticana, Borg. Ilir. 10.

BrVat $_{19}=$ Vatikanski brevijar Vat. Slav. 19, 1465. g., Rim, Biblioteca Apostolica Vaticana, Vat. Slav. 19.

$\mathrm{BrVb}_{1}=$ I. vrbnički brevijar, 13. - 14. st., Vrbnik, Župni ured.

BrVin = Vinodolski (Kukuljevićev) brevijar, 1485. g., Zagreb, HAZU, I d 34 (Kuk I).

BrVO = Brevijar Vida Omišljanina, 1396. g., Beč, Österreichische Nationalbibliothek, Cod. slav. 3. 
A. MIHALJEVIĆ, Služba u čast sv. Tomi Becketu u hrvatskoglagoljskim ... SLOVO 70 (2020)

\section{LATINSKI IZVORI}

BrSar = Breviarium ad Usum Insignis Ecclesiae Sarum. Tekst latinske službe u čast sv . Tomi Becketu preuzet je iz: BRAINERD SLOCUM 2004: 212-214.

\section{LITERATURA}

BRAINERD SLOCUM, K. 2004. Liturgies in Honour of Thomas Becket. Toronto - Buffalo - London: University of Toronto Press.

CHRISTUS REX. 2013. Razlike između tradicionalne latinske Mise i NO / protestantskog bogoslužja. URL: http://christusrexhrvatska.blogspot.com/2013/10/razlike-izmeutradicionalne-latinske.html (17. 11. 2019.).

CORIN, A. R. 1997. O reformama hrvatskoglagoljskih liturgijskih knjiga u 13. stoljeću. S. Damjanović i dr. (ur.). Prvi hrvatski slavistički kongres: Zbornik radova I. Zagreb: HFD, 527-538.

CUZZOLIN, P. 1994. Sull' origine della costruzione dicere quod. Aspetti sintattici e semantici. Firenze: La Nuova Italia.

CUZZOLIN, P. 2013.a. Some remarks on quia as a subordinator after verbs of saying and thinking. Journal of Latin Linguistics 12(1): 51-69.

CUZZOLIN, P. 2013.b. The Latin construction dicere quod revisited. Graeco-Latina Brunensia 18/1: 23-38.

FARMER, D. H. 1987. The Oxford Dictionary of Saints: Second Edition. Oxford: Oxford University Press.

GADŽIJEVA, S.; A. KOVAČEVIĆ; M. MIHALJEVIĆ; S. POŽAR; J. REINHART; M. ŠIMIĆ; J. VINCE. 2014. Hrvatski crkvenoslavenski jezik. Zagreb: Hrvatska sveučilišna naklada - Staroslavenski institut.

GORTAN, V.; O. GORSKI; P. PAUŠ. 2004. Latinska gramatika. Zagreb: Školska knjiga.

GORYS, E. 2003. Leksikon svetaca. Jastrebarsko: Naklada Slap.

HAMM, J. 1953. Varijante u prijepisima hrvatskih glagoljaša. Slovo 2: 13-36.

KOVAČEVIĆ, A.; M. MIHALJEVIĆ; S. SUDEC. 2010. Hrvatski crkvenoslavenski prijevod tekstova sv. Tome Akvinskoga. Slovo 60: 359-476.

MAREŠ, F. V. 1985. A Basic Reform of the Orthography at the Early Period of CroatianGlagolitic Church Slavonic. G. Stone i D. Worth (ur.). The Formation of the Slavonic Literary Languages. Columbus, Ohio: Slavica Publishers, 177-181.

MIHALJEVIĆ, M. 2009. (Ortho)graphic Reforms in Croatian Glagolitic Texts. E. Zašev (ur.). Sbornik s dokladi ot Meždunarodnata konferencija »Glagolica i kirilica - istorija i pismeni pametnici«, Bratislava 6-7 juni 2007 g. Bratislava: Bălgarskija kulturen institut v Bratislava, $1-11$. 
A. MIHALJEVIĆ, Služba u čast sv. Tomi Becketu u hrvatskoglagoljskim ... SLOVO 70 (2020)

MIHALJEVIĆ, M. 2018. Jezik najstarijih hrvatskoglagoljskih rukopisa. Zagreb: Hrvatska sveučilišna naklada - Staroslavenski institut.

REAMES, S. 2000. Liturgical Offices for the Cult of St. Thomas Becket. T. F. Head (ed.). Medieval Hagiography: An Anthology. New York: Psychology Press, 561-593.

TANDARIĆ, J. L. 1993. Hrvatskoglagoljska liturgijska književnost. Zagreb: Kršćanska sadašnjost - Provincijalat franjevaca trećoredaca.

VAJS, J. 1903. Liber Iob. Krk: Staroslavenska akademija.

WEBSTER, P.; M.-P. GELIN (ed.). 2016. The Cult of St Thomas Becket in the Plantagenet World, c. 1170-c. 1220. Woodbridge: The Boydell Press.

\section{Sum mary}

Ana Mihaljević

\section{THE SERVICE IN THE HONOR OF ST. THOMAS BECKET IN CROATO-GLAGOLITIC BREVIARIES}

This paper analyses the language of the Croatian Church Slavonic translation of the Service in the Honor of St. Thomas Becket. The text of the Service in the Honor of St. Thomas Becket has been preserved in 21 Croato-Glagolitic breviaries ( $\mathrm{Vb}_{1}, \mathrm{Bar}, \mathrm{Ber}_{2}, \mathrm{Mosk}, \mathrm{N}_{1}, \mathrm{Vat}_{10}$, Vat ${ }_{19}, \mathrm{Vat}_{5}$, Pm, Met, Mav, VO, Rom, Pt, Broz, Drag, Oxf, Pad, Vin, $\mathrm{N}_{2}$, Brit) in the Proprium de tempore. Thomas Becket was a saint celebrated by the Catholic Church who lived in the $12^{\text {th }}$ century and Croato-Glagolitic scribes could not use an older Slavonic text nor could they translate the text from an eastern protograph. They had to translate the text from the Latin original. The text was translated from the Latin Sarum service. The text of the Service is presented at the end of the paper and in the critical apparatus the differences between all known Croato-Glagolitic sources are given. The majority of differences are phonological and morphological and only rarely lexical. The Croato-Glagolitic text is a translation of the first two and a half readings from the Sarum service. The texts from Oxf, Pm, and Vat ${ }_{10}$ are significantly shorter than the rest of the texts. The text in $\mathrm{Vat}_{19}$ is somewhat shorter and the texts in Bar, Mav, and Broz are slightly shorter than the rest of the texts. Some texts omit or add certain words. The translation is quite literal. There are some parts of sentences and phrases that are not translated. A special problem is how to translate certain forms and structures which do not have the same meaning or function in Latin and Croatian Church Slavonic, especially constructions, dependent clauses, and forms that do not exist in Croatian Church Slavonic. Ablative absolute is mostly translated by a finite clause with or without the conjunction $i$ or by an instrumental absolute. Construction nominativus cum infinitivo with the verb video, 2 is translated in one example as a sentence with the adverb očito and in another example with the impersonal form of the verb vidêt $i$ and the infinitive. The gerundive which replaces gerund is translated as a verbal noun. Conjunction quia in this text is a conjunction of causal clauses and is translated as conjunction $\hat{e} k o$. Latin conjunctive imperfect in Croato-Glagolitic texts is often translated as conditional, but in the declarative clause, it is translated as an indicative. Conjunctive imperfect of periphrastic conjugation active is translated as an infinitive with the imperfect of the verb imati. Construction accusativus cum infinitivo is mostly translated literally, especially in sentences that express a command. The conjunctive present is translated with an indicative. The word 
order of the translation mostly follows the Latin word order. The text was probably translated at the end of the $13^{\text {th }}$ century because of the fact that St. Thomas Becket lived at the end of the $12^{\text {th }}$ century and the oldest preserved Croato-Glagolitic service in his honor from $\mathrm{Vb}_{1}$ is from the end of the $13^{\text {th }}$ or the beginning of the $14^{\text {th }}$ century.

Key w ord s: The Service in Honour of St. Thomas Becket, Croatian Church Slavonic, CroatoGlagolitic breviaries, Latin template, translation technique

\author{
Ana Mihaljević \\ Old Church Slavonic Institute \\ Zagreb (Croatia) \\ ana.mihaljevic@stin.hr
}

